\title{
The importance of wind forcing in fjord wave modelling
}

\author{
Konstantinos Christakos ${ }^{1,2}$ (D) Birgitte R. Furevik ${ }^{1,3}$. Ole Johan Aarnes ${ }^{1} \cdot \emptyset_{\text {yvind Breivik }}^{1,2}$ • Laura Tuomi ${ }^{4}$. \\ Øyvind Byrkjedal ${ }^{5}$
}

Received: 21 June 2019 / Accepted: 5 November 2019 / Published online: 3 December 2019

(C) The Author(s) 2019

\begin{abstract}
Accurate predictions of surface ocean waves in coastal areas are important for a number of marine activities. In complex coastlines with islands and fjords, the quality of wind forcing significantly affects the results. We investigate the role of wind forcing on wave conditions in a fjord system partly exposed to open sea. For this reason, we implemented the wave model SWAN at the west coast of Norway using four different wind forcing. Wind and wave estimates were compared with observations from five measurement sites. The best results in terms of significant wave height are found at the sites exposed to offshore conditions using a wind input that is biased slightly high compared with the buoy observations. Positively biased wind input, on the other hand, leads to significant overestimation of significant wave height in more sheltered locations. The model also shows a poorer performance for mean wave period in these locations. Statistical results are supported by two case studies which also illustrate the effect of high spatial resolution in wind forcing. Detailed wind forcing is necessary in order to obtain a realistic wind field in complex fjord terrain, but wind channelling and lee effects may have unpredictable effects on the wave simulations. Pure wave propagation (no wind forcing) is not able to reproduce the highest significant wave height in any of the locations.
\end{abstract}

Keywords Fjord · Wave modelling · Wind forcing · SWAN

\section{Introduction}

During the last decades, wave forecasts based on spectral wave models have achieved a high level of reliability in open seas. Wave parameters such as significant wave height, wave period, and direction can be predicted with high accuracy up to a week in advance (e.g., Bidlot et al.

Responsible Editor: Bruno Castelle

Konstantinos Christakos

konstantinos.christakos@met.no

1 Norwegian Meteorological Institute, Allegaten 70, 5020, Bergen, Norway

2 Geophysical Institute, University of Bergen, Allegaten 70, 5020, Bergen, Norway

3 Danish Meteorological Institute, Lyngbyvej 100, 2100, Copenhagen, Denmark

4 Finnish Meteorological Institute, Erik Palménin aukio 1, 00560, Helsinki, Finland

5 Kjeller Vindteknikk AS, Gunnar Randers vei 24, 2027, Kjeller, Norway
2002; Janssen 2008, 2018). This has been achieved mainly through systematic development of numerical weather prediction models providing reliable wind input to wave models, and by recent improvements in the wind input and dissipation source terms (Babanin 2011) of wave models. Wave observations from satellite altimeters have been used extensively for calibration of wave models (Cavaleri and Sclavo 2006; Martínez-Asensio et al. 2013) providing wave data in over large ocean areas where buoy measurements are unavailable. Nowadays, the most widely used third generation spectral wave models are the Wave Model (WAM) (The Wamdi Group 1988), the Simulating WAves Nearshore model (SWAN) (Booij et al. 1999), and the WaveWatch-III model (The WAVEWATCHIII ${ }^{\circledR}$ Development Group 2016). Several studies based on these models have shown quite accurate results for open-ocean conditions (e.g., Reistad et al. 2011; Bertotti et al. 2014; Galanis et al. 2019; Amarouche et al. 2019; Stopa and Cheung 2014; Guedes Soares et al. 2016).

Despite these improvements, the quality of the wave forecasts is still not sufficient in the coastal and semienclosed seas (Cavaleri et al. 2018). Their performance has not been extensively evaluated in complex coastal areas and 
their results cannot be used with as high level of reliability as for the open sea. The coastal topography affects the quality of simulated wind fields and consequently the wave fields. In addition, the presence of islands and shallow water areas makes the wave prediction more complicated. Moreover, for validation purposes, coastal observations are limited to point measurements (e.g., wave buoys) since remote sensing instruments such as satellite altimeters in coastal areas are not as reliable as in the open sea. This is mainly because the raw measurements are contaminated by land (Vignudelli et al. 2011).

Accurate wave predictions in coastal areas are essential for a number of coastal activities, e.g., infrastructure, maritime transport, aquaculture, and renewable energy applications. Furthermore, for coastal applications, information on both swell and wind sea is important. For instance, prediction of locally generated wind sea is essential for high-speed passenger ferries whereas information about the propagation of low-frequency swell in coastal areas and fjords is critical for the design of coastal structures or in the planning of marine operations.

When designing coastal structures or planning marine operations, it is important to know the wave conditions both in a statistical sense and in being able to forecast the wave conditions days ahead. In areas where swell have a strong influence and where extreme values of significant wave height and peak period due to storm conditions are of main interest, relatively good results may be obtained by propagation to coast of actual or parameter-based offshore spectra using a wave model or by establishing a statistical relationship between offshore hindcast and local wave measurements (Wang et al. 2018). As constructions become larger, or when marine operations or coastline are complex, more sophisticated methods that include the effect of local wind must be applied.

Global reanalyses (Laloyaux et al. 2018; Hersbach and Dee 2016; Poli et al. 2016) yield wind fields that can be used for wave applications. However, several studies show the importance of resolution in order to achieve accurate wave hindcasts. Lavidas et al. (2017) studied the sensitivity of wind input on a wave model for the Scottish region showing that the use of different reanalysis wind fields (ERA-Interim (Dee et al. 2011) and CFSR-NCEP (Saha et al. 2010) can significantly affect the quality of wave hindcasts. Moeini et al. (2010) assessed the quality of surface winds for wave simulations using SWAN in the Persian Gulf and found that ECMWF winds are underestimated and consequently that the wave model must be calibrated. Signell et al. (2005) studied the quality of four wind fields with different spatial resolution in the Adriatic Sea. They employed the SWAN model and similarly found that ECMWF wind fields are biased low. In addition to more realistic small-scale and spatial structure of wind fields during strong wind events, the higher resolution models showed better over all performance for both wind speed and wave heights. Ponce de León et al. (2012) assessed four atmospheric models around the Balearic Islands for operational wave forecast. They conclude that spatial variability of wind forcing is a key factor for the small-scale features which coarse resolution models are not able to resolve. Ardhuin et al. (2007) studied the performance of four atmosphere models and three spectral wave models finding that quality of the wind input degrades approaching coastal areas, especially in cases with orographic effects.

On complex coastlines, as in archipelagos or fjord systems, wave modeling is a discipline of combining good offshore wave forecast with local wave production (Tuomi 2014a). In the transition zone from sheltered areas to swell-dominated outer parts, local wind may play a role in different ways. The ability of wave models to respond accurately to the local wind in combination with swell in such transition zones is the focus of the present study. The main objective of this study is to investigate the role of wind forcing on wave conditions in a semi-enclosed environment such as a fjord system. The study focuses on the effect of coastal wind forcing on wave simulations inside the fjord system which is located on the west coast of Norway.

This paper is organised as follows. Section 2 is dedicated to the wave climate of our study area. Section 3 describes the data and methods. The evaluation of models and the results are presented in Section 4. Finally, Section 5 includes the discussion and Section 6 is following with the conclusions.

\section{Background}

\subsection{Study area}

The study is focused on a fjord system with several bifurcations located at the West coast of Norway (Fig. 1a). Figure 2a illustrates a terrain map with the bathymetry provided by the European Marine Observation and Data Network (EMODnet 2016) applied for SWAN wave simulations. It shows the two nested domains, the outer domain (D1), and the inner domain (D2) marked with a red rectangle. D1 spans the region $62 \mathrm{~N}^{\circ}$ to $63.14 \mathrm{~N}^{\circ}$, and 5 $\mathrm{E}^{\circ}$ to $8.12 \mathrm{E}^{\circ}$. D2 shown in Fig. $2 \mathrm{~b}$ contains the following fjords: Storfjorden (1), Hjørundfjorden (2), Sulafjorden (3), Vartdalsfjorden (4), Voldsfjorden (5), and Rovdefjorden (6) and measurement locations A, B, C, D, and F. Table 1 shows the fjord characteristics such as average length, width and depth range with the corresponding numbers as illustrated in Fig. 2b. The fjord system is more than $190 \mathrm{~m}$ deep at its deepest points. The longest fjords are Storfjorden and Hjørundfjorden, exceeding 30-km length. The shortest and widest fjord is Sulafjorden with $10-\mathrm{km}$ 
Fig. 1 The location of the study area (rectangular) in the west coast of Norway (a). The area consists of islands and islets outside the fjord system. The directional roses show the frequency of waves at certain peak directions for total $H_{\mathrm{S}}(\mathbf{b})$, swell (c), and wind sea (d) components at a point (blue star) based on NORA10 dataset for the period: 09.1957-07.2018. Colors in directional roses: dark blue for $H_{\mathrm{s}} 0-1.99 \mathrm{~m}$, light blue for $H_{\mathrm{s}} 2-3.99 \mathrm{~m}$, green for $H_{\mathrm{s}}$ 4-5.99 m, and yellow for $H_{\mathrm{s}}>6 \mathrm{~m}$

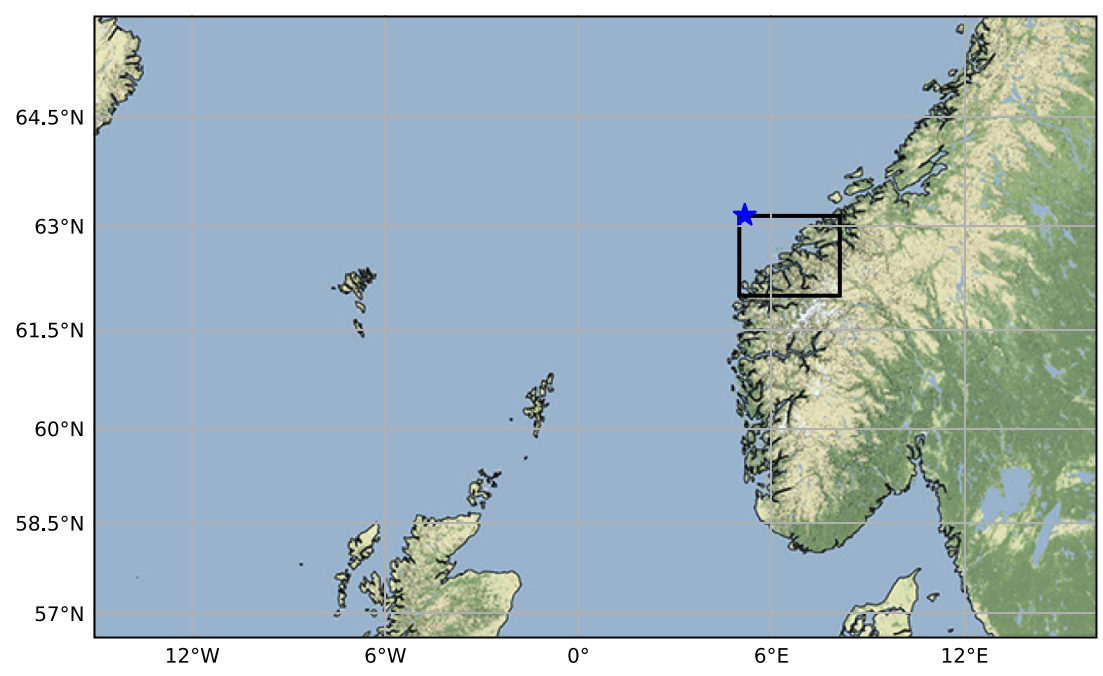

(a)

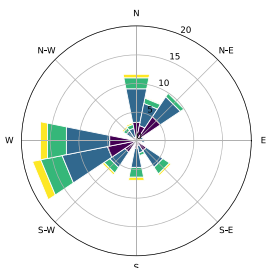

(b)

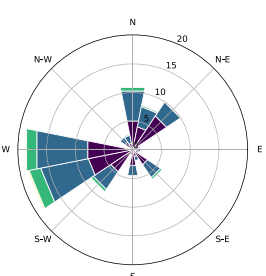

(c)

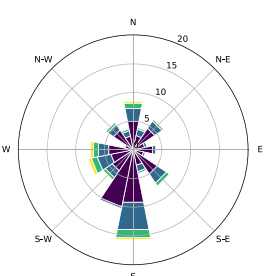

(d) average length and 4.6-km average width. Its narrowest part is $3.20 \mathrm{~km}$ (offshore inlet) and the widest part at $6 \mathrm{~km}$ (cross section with Vartdalsfjorden). Sulafjorden is the only part of this fjord system that has a direct exposure to open sea conditions.

\subsection{Wave climate: offshore vs. fjord system}

Varlas et al. (2017) investigated the marine renewable resources along the Norwegian coast and found the highest average values of wave energy flux over the Norwegian Sea (close to our study area) where swell waves have the largest contribution to total wave energy. Similarly, Aarnes et al. (2012) showed that Sulafjorden is situated in an area where wave energy generated in the Northeast Atlantic is let between the Faroes and Shetland, making this area one of the most exposed areas for extreme wave heights along the Norwegian coast. Close to this area, Christakos et al. (2014) studied the atmospheric phenomenon of a coastal low-level jet illustrating the need of a high-resolution model to predict the strong coastal winds and horizontal shear of the jet. The wave climate off the fjord system is characterized by a combination of swell and wind sea conditions (Reistad et al. 2011; Semedo et al. 2015). Figure 1 shows the directional roses for total, swell, and wind sea significant wave height $\left(H_{\mathrm{S}}\right)$ at an offshore hindcast point in NORA10 (Norwegian
Fig. 2 a Bathymetry of model outer (D1) and inner (D2) domains used for the wave simulations. The color bar shows the depth in meters b D2 of wave simulations. The numbers indicate the fjords (see Table 1) and the letters the positions of wave buoys (see Table 3 )

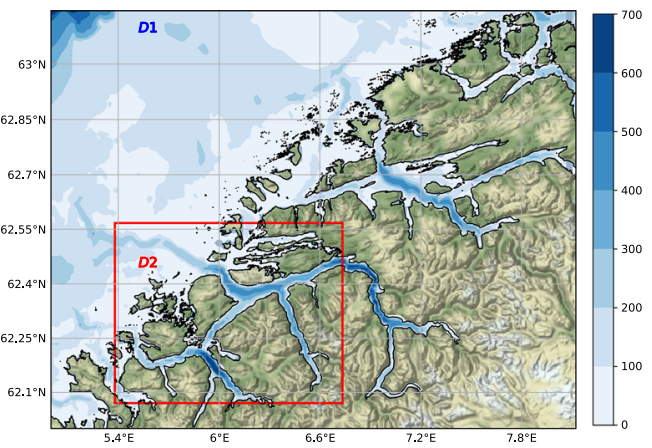

(a)

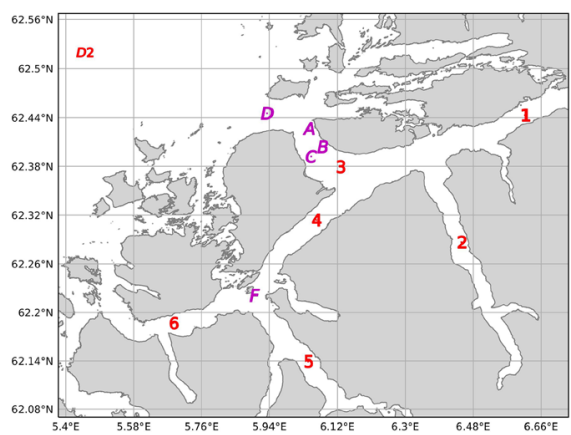

(b) 
Table 1 The characteristics of fjord system: average length (L), average width (W), and depth range (D), data derived by The Norwegian Coastal Administration (2019a)

\begin{tabular}{lllll}
\hline No. & Fjord & L $(\mathrm{km})$ & $\mathrm{W}(\mathrm{km})$ & $\mathrm{D}(\mathrm{m})$ \\
\hline 1 & Storfjorden & 35 & 2.7 & $250-650$ \\
2 & Hjørundfjorden & 31 & 2.1 & $190-440$ \\
3 & Sulafjorden & 10 & 4.6 & $230-450$ \\
4 & Vartdalsfjorden & 21 & 3.0 & $230-360$ \\
5 & Voldsfjorden & 25 & 2.5 & $320-680$ \\
6 & Rovdefjorden & 17 & 2.6 & $370-490$ \\
\hline
\end{tabular}

hindcast of wind and waves) where its wave component is the WAM model (Reistad et al. 2011). WAM defines the wave components that are still subject to wind forcing as wind sea while the rest part of the spectrum is defined as swell (ECMWF 2018).

Regarding total $H_{\mathrm{s}}$, the dominant wave direction is west-southwest with a secondary direction from northnortheast. Separating the total $H_{\mathrm{s}}$ into swell and wind sea components, we observe the dominance of swell over wind sea component. The incoming swell from southwest and northeast is contributing the most to the wave conditions in the area. The directional distribution for wind sea is more scattered with a dominant direction from south and a secondary direction from north. It is noteworthy that the dominant southerly wind sea component is not observed in the total $H_{\mathrm{s}}$ rose. This feature can be explained by the fact that southerly wind sea is often accompanied by south/southwesterly swell, which dominates the total wave direction. However, the wave climate close to the coast and within the fjords is quite different. Figure 3 presents the directional wave distributions based on observations in Sulafjorden. The distributions are much more narrow compared with offshore conditions. This is mainly due to the presence of islands off the fjord system and the narrow fjord geometry (which funnels and speeds up the air flow) with short fetches that affect the shape of directional distribution.

\section{Data and methods}

\subsection{Atmospheric models}

Surface winds from four different atmospheric models, including the ERA5 reanalysis (Copernicus Climate Change Service (C3S) 2017), NORA10 hindcast archive (Reistad
Fig. 3 The directional roses show the frequency of waves for $H_{\mathrm{S}}$ at location $\mathrm{D}, \mathrm{A}, \mathrm{B}$, and $\mathrm{C}$. Colors in directional roses: dark blue for $H_{\mathrm{s}} 0-0.99 \mathrm{~m}$, light blue for $H_{\mathrm{s}} 1-1.99 \mathrm{~m}$, green for $H_{\mathrm{s}}$ 2-2.99 $\mathrm{m}$, and yellow for $H_{\mathrm{s}}>3 \mathrm{~m}$

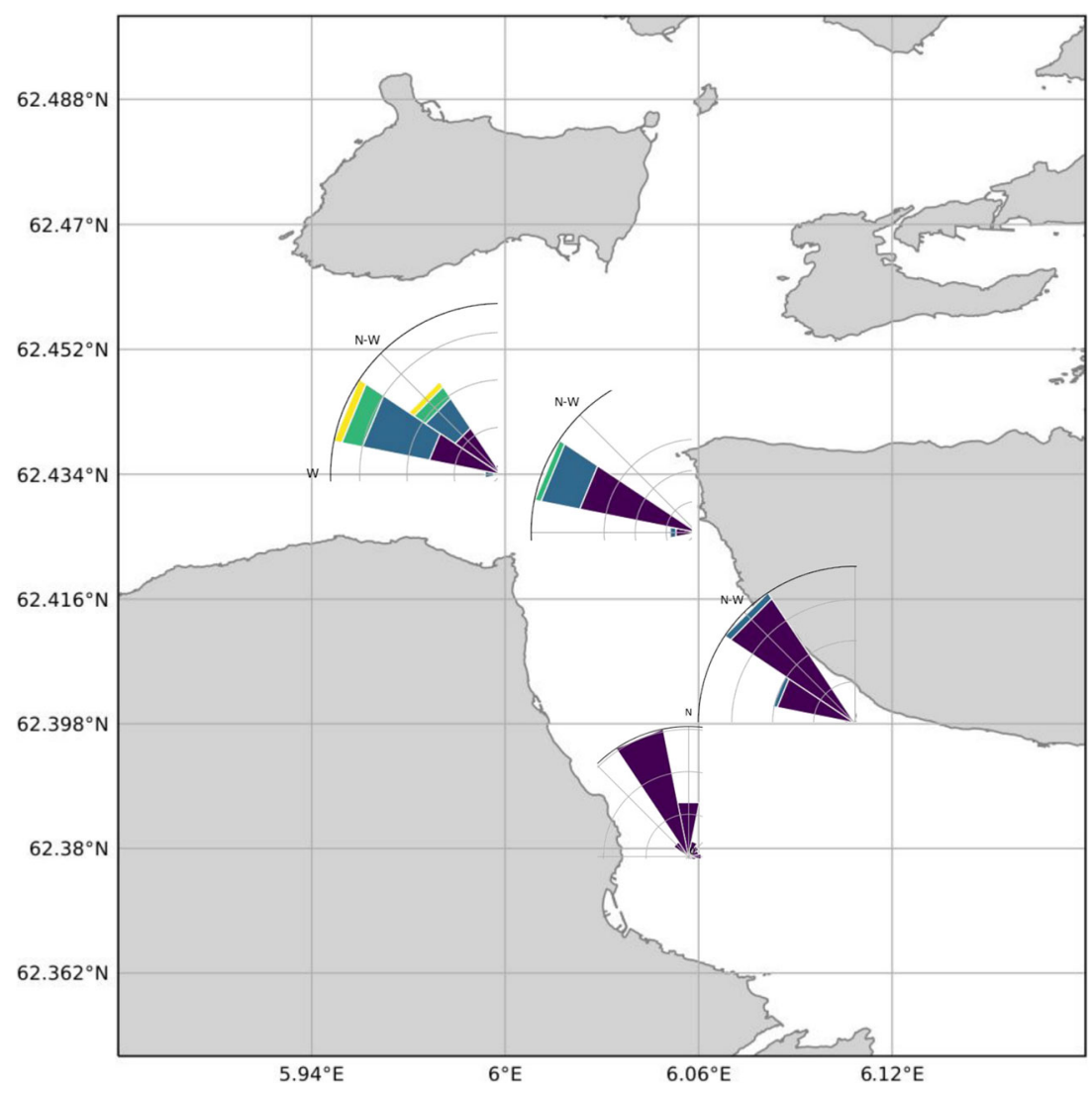


et al. 2011), AROME2.5 operational model (Müller et al. 2017), and WRF (Skamarock et al. 2008) are used for wave simulations in our study area.

\subsubsection{WRF0.5}

The WRF-ARW (Advanced Research WRF) (Skamarock et al. 2008) state-of-the-art numerical weather prediction model version 3.5.0 was used to downscale the reanalysis ERA-Interim (Dee et al. 2011) to a spatial resolution of $0.5 \mathrm{~km}$ for the study area. Four domains were used with two-way nesting. The parent domain is covering a large part of the North Atlantic, including the North Sea and the Norwegian Sea, with a horizontal resolution of $22.5 \mathrm{~km}$. The second domain has a resolution of $4.5 \mathrm{~km}$ covering the south part of Norway and part of the Norwegian and the North Sea. The third domain has $1.5-\mathrm{km}$ horizontal resolution and the innermost domain is focused on our region of interest with a resolution of $0.5 \mathrm{~km}$. The model has been run with 51 vertical levels and approximately 8 levels within the lower $200 \mathrm{~m}$ of the atmosphere. The basic parameterization schemes applied for this hindcast are the following: Thompson microphysics, Rapid Radiative Transfer Model (RRTM) radiation scheme, and MellorYamada-Janjic (MYJ) which is used for the vertical mixing in the boundary layer. A thermal diffusion scheme is used for the surface and the SST used is from ERA interim and updated daily. No cumulus parameterization is applied to the two inner domains, but the KainFritsch scheme is used for the two outer domains. The surface wind calculated by WRF-ARW at $10 \mathrm{~m}$ above terrain for the 19-month period and applied as input to SWAN. The corresponding wave simulation is referred as SWAN-WRF0.5.

\subsubsection{AROME 2.5 (AR2.5)}

The Application of Research to Operations at Mesoscale (AROME) model is the core of the operational weather prediction model employed at MET Norway (Müller et al. 2017). The model is set up for the MetCoOp-domain with $2.5-\mathrm{km}$ grid spacing and 65 levels. The forecasting suite consists of main forecast cycles at 00 and 12 UTC and intermediate cycles at 06 and 18 UTC. The analysis times of the European Centre for Medium-Range Forecasts (ECMWF) Integrated Forecasting System (IFS) forecasts used as boundaries for the main and intermediate cycles are 6 and $3 \mathrm{~h}$ earlier, respectively (Müller et al. 2017). The surface wind calculated by AROME at $10 \mathrm{~m}$ above terrain in 6-h forecasts from +3 to +8 from each of the cycles is put together for the 19-month period and used as input to SWAN. The corresponding wave simulation is referred as SWAN-AR2.5.

\subsubsection{NORA10}

NORA10, wind and wave hindcast developed by The Norwegian Meteorological Institute, covers the Norwegian Sea, Barents Sea, and the North Sea (Reistad et al. 2011). The atmospheric model is HIRLAM (High Resolution Limited-Area Model) (Undén et al. 2002) with 10-km horizontal resolution on a rotated spherical grid. The surface winds from HIRLAM are forcing the wave model WAM on the same grid, as described in Section 3.4. HIRLAM is set up with 40 vertical layers and is a dynamical downscaling of ERA-40 (Uppala et al. 2005) and ECMWF-IFS after September 2002. Further description of the model set-up is found in Bjørge et al. (2003). Winds from NORA10 are improved compared with ERA-40 and show good agreement against observations particularly in the coastal areas, e.g. Reistad et al. (2011) and Furevik and Haakenstad (2012). The corresponding wave simulation is referred as SWAN-NORA10.

\subsubsection{ERA5}

ERA5 (Hersbach and Dee 2016; Copernicus Climate Change Service (C3S) 2017) is the latest climate reanalysis product by ECMWF. The data set is available in the Climate Data Store on regular latitude-longitude grids at a horizontal resolution of about $31 \mathrm{~km}$ and 1-hour time steps. ERA5 data has finer horizontal and temporal resolution than its predecessor ERA-Interim (Dee et al. 2011) (about $80 \mathrm{~km}$ and 6-hourly). Several studies have shown the improvement of ERA5 winds relative to ERA interim. Belmonte Rivas and Stoffelen (2019) compared ASCAT wind observations to ERA5 and ERA interim, concluding that ERA5 shows better performance. Olauson (2018) performed a comparison of MERRA-2 (ModernEra Retrospective analysis for Research and Applications, Version 2) (Gelaro et al. 2017) and ERA5 datasets in terms of wind power, also concluding that ERA5 performs better. The corresponding wave simulation is referred as SWAN-ERA5.

\subsubsection{No wind forcing (NWF)}

An additional run with no wind forcing (NWF) is performed to visualize the dependency on the accurate description of incoming swell and the importance of local winds in the fjord system. The corresponding wave simulation is referred as SWAN-NWF.

\subsection{Error metrics-taylor diagram}

In order to illustrate error metrics at different locations, a Taylor diagram (Taylor 2001) is utilized. The error metrics 
of the correlation coefficient $(R)$, normalized standard deviation (NSTD), and the normalized centered root means square error (CRMSE) are implemented in Fig. 4 for wind speed and significant wave height:

$$
\begin{aligned}
& R=\frac{\sum_{i=1}^{N}\left(y_{i}-\bar{y}\right)\left(x_{i}-\bar{x}\right)}{\sqrt{\sum_{i=1}^{N}\left(y_{i}-\bar{y}\right)^{2}} \sqrt{\sum_{i=1}^{N}\left(x_{i}-\bar{x}\right)^{2}}} \\
& N S T D=\frac{\sqrt{\frac{1}{N} \sum_{i=1}^{N}\left(y_{i}-\bar{y}\right)^{2}}}{\sqrt{\frac{1}{N} \sum_{i=1}^{N}\left(x_{i}-\bar{x}\right)^{2}}} \\
& C R M S E=\frac{\sqrt{\frac{1}{N} \sum_{i=1}^{N}\left[\left(y_{i}-\bar{y}\right)-\left(x_{i}-\bar{x}\right)\right]^{2}}}{\sqrt{\frac{1}{N} \sum_{i=1}^{N}\left(x_{i}-\bar{x}\right)^{2}}}
\end{aligned}
$$

where $y_{i}$ are the model estimate, $x_{i}$ are the observations, $\bar{y}$ and $\bar{x}$ the mean values, and $N$ indicates the number of data pairs. The normalized parameters allow comparison along different areas within the fjord system.

\subsection{The SWAN wave model}

The wave model SWAN (Booij et al. 1999) is a stateof-the-art third generation spectral model designed for nearshore applications. SWAN is widely used for both operational and engineering applications. For this study, we implemented the SWAN cycle III version 41.20. SWAN is based on an implicit propagation scheme which is always numerically stable. Therefore, the SWAN model is suitable for simulating wave conditions in coastal and semi-enclosed environments where the grid resolution and thus the time step must be relatively small. The model propagates the action balance equation forward in time for the evolution of action density spectrum $(N)$ :

$\frac{\partial N}{\partial t}+\frac{\partial\left(c_{x} N\right)}{\partial x}+\frac{\partial\left(c_{y} N\right)}{\partial y}+\frac{\partial\left(c_{\sigma} N\right)}{\partial \sigma}+\frac{\partial\left(c_{\theta} N\right)}{\partial \theta}=\frac{S}{\sigma}$

where $c_{x}$ and $c_{y}$ are the propagation group velocities in geographical $(x, y)$-space, respectively. The $c_{\sigma}$ and $c_{\theta}$ represent the propagation in spectral (frequency$\sigma$, direction- $\theta)$ space. The term $S(\sigma, \theta ; x, y, t)$ is the total source term. It consists of three source terms,

$S=S_{i n}+S_{d s}+S_{n l}$

Here, $S_{i n}$ is energy input generation due to wind, $S_{d s}$ is the dissipation induced by whitecapping, bottom friction and depth-induced wave breaking. Finally, $S_{n l}$ represents non-linear wave-wave interactions.

The model was run in non-stationary mode with spherical coordinates and a time step of $10 \mathrm{~min}$. Thirty-six directions with $10^{\circ}$ directional resolution and 32 discrete frequencies from 0.04 to $1 \mathrm{~Hz}$ were used as presented in Table 2 . The inner domain with $250 \mathrm{~m} \times 250 \mathrm{~m}$ (red rectangular
Table 2 Model grid

\begin{tabular}{ll}
\hline Component & Grid definition \\
\hline Directional resolution $\Delta \theta$ & $10^{\circ}$ \\
Frequency range & $0.04-1 \mathrm{~Hz}$ \\
Spatial resolution $(\Delta x, \Delta y)$ & \\
Outer domain & $1 \mathrm{~km} \times 1 \mathrm{~km}$ \\
Inner domain & $250 \mathrm{~m} \times 250 \mathrm{~m}$ \\
\hline
\end{tabular}

in Fig. 2a) grid cells is nested into the outer grid of $1 \mathrm{~km} \times 1 \mathrm{~km}$ (Fig. 2a). The wave simulation period is from 01.10.2016 until 30.04.2018. The combination of the formulation by Yan (1987) for wind growth and non-linear saturation-based whitecapping based on Alves and Banner (2003) implemented in SWAN by van der Westhuysen et al. (2007) was chosen. According to the model modification page (in version 40.51 SWAN team 2019), this combination is more suitable for young waves than the default expression (Komen and Hasselmann 1984), offering a way to resolve the erroneous behavior of SWAN under combined swellsea conditions (conditions that describe the wave climate in our study area). The bottom friction term is by Hasselmann et al. (1973) and depth-induced wave breaking by Battjes and Janssen (1978).

\subsection{Boundary spectra}

Spectral wave boundary conditions along the grid boundaries of the outer domain (D1) were in all simulations obtained from the NORA10 hindcast with 3-h temporal resolution (for details on the spectral nesting and interpolation procedure, see Breivik et al. 2009). The wave component of NORA10 is a 10-km WAM model forced with HIRLAM winds nested inside a 50-km North Atlantic WAM model forced by ERA-40 winds (Reistad et al. 2011). The wave component is a modified version of the WAM cycle 4 model (Gunther and Janssen 1992) set up on the same rotated spherical grid as HIRLAM. The outer domain of 50$\mathrm{km}$ resolution covers the North Atlantic, allowing realistic swell propagation from the North Atlantic to the Norwegian coast. Twenty-four directional bins and 25 frequencies $(0.0420$ to $0.4137 \mathrm{~Hz})$ were used for the model set-up. The quality of NORA10 wave hindcast has been evaluated through several studies. According to Aarnes et al. (2012), a low bias of significant wave height between NORA10 and observations located in the North Sea and the Norwegian Sea is observed. Bruserud and Haver (2016) found a good agreement between NORA10 and wave observations in the northern part of North Sea. Based on its good performance in open sea conditions, NORA10 is believed to provide reliable boundary data for the coastal wave model. 
Table 3 Mean and P99.9 of observed $H_{\mathrm{S}}(\mathrm{m})$ and wind speed $-\mathrm{U}\left(\mathrm{m} \mathrm{s}^{-1}\right)$ at locations D, A, B, C, and F

\begin{tabular}{lllllll}
\hline Buoy & Latitude, longitude & Period & $\bar{H}_{S}$ & $P 99.9: H_{S}$ & $\bar{U}$ & $P 99.9: U$ \\
\hline D & $62.45,5.93$ & $10.2016-04.2018$ & 1.3 & 5.8 & 5.8 & 16.7 \\
A & $62.43,6.04$ & $10.2016-04.2018$ & 0.8 & 3.4 & 5.1 & 16.5 \\
B & $62.40,6.08$ & $10.2016-04.2018$ & 0.4 & 2.1 & 3.8 & 15.3 \\
C & $62.39,6.05$ & $04.2017-04.2018$ & 0.2 & 0.9 & 3.9 & 14.4 \\
F & $62.22,5.90$ & $11.2017-04.2018$ & 0.2 & 1.0 & 5.3 & 15.7 \\
\hline
\end{tabular}

\subsection{Observations}

Wind and wave measurement data from SEAWATCH Wavescan buoys (FUGRO 2012) were available via MET Norway Thredds Service (The Norwegian Meteorological Institute 2019b) to evaluate the performance of numerical simulations. The measurement data contains integrated wave parameters such as significant wave height, peak wave period, mean wave period, mean wave direction, as well as wind speed and wind direction. The wind sensors are placed $4.1 \mathrm{~m}$ above the sea level. The wave buoys $\mathrm{D}, \mathrm{A}$, $\mathrm{B}$, and $\mathrm{C}$ are deployed in Sulafjorden and the buoy $\mathrm{F}$ in Vartdalsfjorden as illustrated in Fig. 2b. Table 3 shows the period of data availability for different wave buoys at the time of this study.

\section{Results}

\subsection{Model validation}

The quality of the wave model runs, their boundary, and wind forcing fields are evaluated by comparing wind speed, $U$, significant wave height, $H_{\mathrm{s}}$, and mean wave period, $T_{m 01}$, against buoy measurements at locations $\mathrm{D}, \mathrm{A}, \mathrm{B}$, C, and F. According to Akpnar et al. (2012), inaccurate conclusions regarding the model performance of mean wave period can occur if the integration range does not match the buoy frequency range. Therefore, $T_{m 01}$ is estimated with the upper integration limit at $0.5 \mathrm{~Hz}$ which is the maximum frequency measured by the buoys. We use the logarithmic wind profile (6) to adjust the model wind speed $\left(U_{10}\right)$ from 10 to $4.1 \mathrm{~m}$ (wind sensor height) above the sea level assuming neutral conditions.

$\frac{U_{2}}{U_{1}}=\frac{\ln \left(\left(z_{2}-d\right) / z_{0}\right)}{\ln \left(\left(z_{1}-d\right) / z_{0}\right)}$

where $U_{1}$ and $U_{2}$ are the wind speed at the elevations of $z_{1}$ and $z_{2}, d$ is the zero-plane displacement and it is considered zero in the fjord, $z_{0}$ is the roughness length which is chosen to be $0.0002 \mathrm{~m}$ for open sea conditions according to revised Davenport roughness classification by Wieringa (1992). Moreover, the classification by Troen and Lundtang Petersen (1989) for water areas, i.e., lakes, fjords, and open sea where the roughness length is in order of $10^{-4}$, and a study focused on fjord wave conditions by Wang et al. (2018) support this choice.

The Taylor diagram for wind speed is presented in Fig. 4a. The different grid axis are the NSTD in light grey circles, the CRMSE in solid grey circles, and the correlation coefficient in lines. The five different symbols denote the different wind input: ERA5 (E), NORA10 (N), AR2.5 (A), WRF0.5 (W), and NWF (circle, $H_{\mathrm{S}}$ only). The colors correspond to different buoy locations. ERA5
Fig. 4 Taylor diagram of error metrics for wind speed - $U$ (a) and $H_{\mathrm{s}}(\mathbf{b})$ for different wave simulations at locations A (blue), B (red), C (green), D (black), and $\mathrm{F}$ (purple). The simulations with different wind forcing are indicated by letters; SWAN-ERA5 (E), SWAN-NORA10 (N), SWAN-AR2.5 (A) and SWAN-WRF0.5 (W). The full circles represents SWAN-NWF

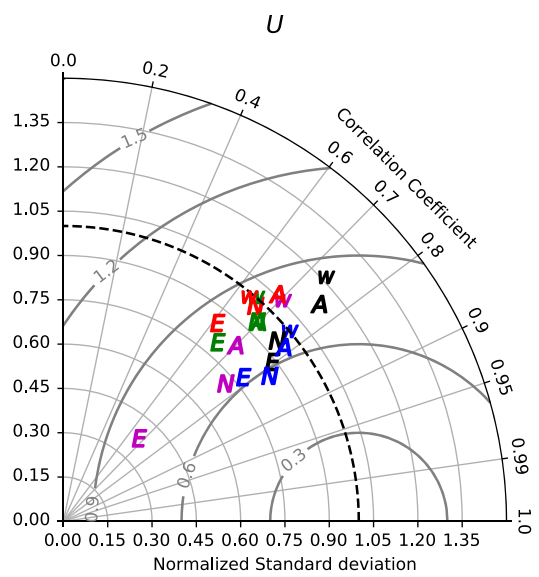

(a)

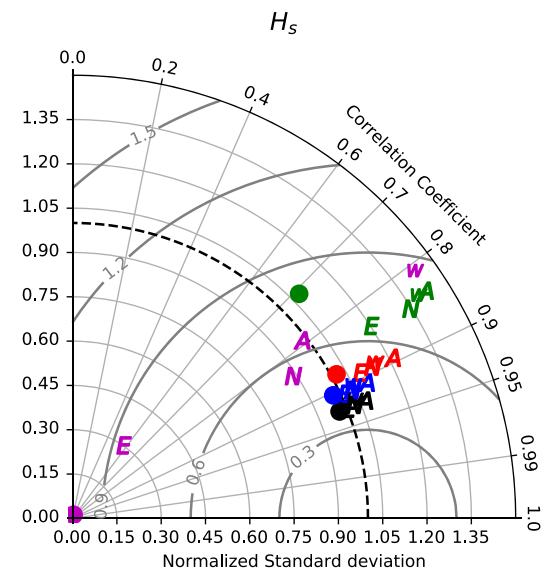

(b) 
winds have the lowest correlation coefficients at the inner fjord locations B, C, and F. ERA5 winds also exhibit too low variability (NSTD) compared with the observations, in particular at location F. WRF0.5 has the best performance in terms of variability at locations A, B, C, and F. For the most exposed location, D, all models perform well, but AR2.5 and WRF0.5 have too high variability (model activity).

Figure $4 \mathrm{~b}$ presents the Taylor diagram for significant wave height. The locations at the inlet of Sulafjorden (D and A) have the best match to the observations. For these locations the simulations with wind forcing do not deviate much from SWAN-NWF for average conditions. The results also show that the correlation coefficient, $R$, is decreasing from exposed to inner locations. More specific, for buoys located in the inlet of Sulafjorden (D and A), the correlation $R$ is greater than 0.9 . For buoys $\mathrm{B}$ and $\mathrm{C}$ located within Sulafjorden, the correlation coefficients are slightly reduced to 0.90 and 0.85 respectively.

The effect of local winds becomes more dominant in location $\mathrm{F}$, where the absence of incoming swell makes the local wind a crucial parameter for wave growth. The results show that SWAN-NORA10 and SWAN-AR2.5 have a correlation coefficient close to 0.80 , the lowest CRMSE and the best NSTD indicating a good match to observed data in this location.

For further investigation of the wave model performance for different wind input, the quantile-quantile $(Q-Q)$ plot is used as illustrated in Fig. 5a, d, g, j, and $\mathrm{m}$ for locations $\mathrm{D}, \mathrm{A}, \mathrm{B}, \mathrm{C}$, and $\mathrm{F}$ respectively. The $Q-Q$ plots show that in most locations, WRF0.5 and AR2.5 have the tendency to overestimate the high wind speeds while NORA10 and ERA5 underestimate.

For wave buoys D and A located at the entrance of Sulafjorden, SWAN-NORA10, SWAN-ERA5, and SWANNWF underestimate $H_{\mathrm{s}}$ for the highest percentiles (Fig. 5b, $\mathrm{e}, \mathrm{h}, \mathrm{k}$, and $\mathrm{n}$ ). On the other hand, wave buoys $\mathrm{B}$ and $\mathrm{C}$ located in the inner part of Sulafjorden, all simulations with wind forcing overestimate $H_{\mathrm{s}}$ in the interval $0.5-1.5 \mathrm{~m}$. The SWAN-NWF shows an underestimation for higher $H_{\mathrm{s}}$.

Simulations of $T_{m 01}$ using SWAN-WRF0.5, SWANAR2.5, SWAN-NORA10, and SWAN-ERA5 over-predict $T_{m 01}$ at locations D, A, B, and C (Fig. 5c, f, i, and 1). The over-prediction is stronger for high $T_{m 01}$. Mean period is predicted fairly well in location F (Fig. 5o). SWAN-NWF clearly overestimates the observed mean wave periods at all locations. This overestimation becomes more pronounced for locations sheltered within the fjord system where the swell conditions are weaker and wind seas are stronger.

The $H_{\mathrm{s}}$ of SWAN-NWF shows that in Sulafjorden the wave system was well described by pure swell input up to certain $H_{\mathrm{s}}$ limit, i.e., $4 \mathrm{~m}$ at $\mathrm{D}, 2 \mathrm{~m}$ at $\mathrm{A}, 1 \mathrm{~m}$ at $\mathrm{B}$, and $0.5 \mathrm{~m}$ at C. For higher values of $H_{\mathrm{s}}$, e.g., during strong wind forcing, the local wind-induced waves become important for the accuracy of wave predictions. Small differences in wind input can generate relative high variations on wave heights at location $\mathrm{F}$. For winds greater than $10 \mathrm{~m} \mathrm{~s}^{-1}$, WRF0.5 slightly overestimates observed wind speed in contrast to AR2.5 and NORA10 that underestimate it. This overestimation by WRF0.5 leads to a relatively high overestimation of $H_{\mathrm{S}}$ which will be investigated more in next section. The weaker winds produced by AROME and NORA10 give better results for $H_{\mathrm{s}}$. ERA5 wind is significantly weaker than observations and this input fails to reproduce the wave conditions.

The use of a nested finer grid improves the quality of results in most of measurement locations (not shown). Especially in location $\mathrm{C}$ where sheltering by the island is dominant, wave parameters such as $H_{\mathrm{S}}$ and $T_{m 01}$ (Fig. 6) were improved using a nested fine grid by $36 \%$ and $4 \%$, respectively.

\subsubsection{Extreme wave conditions in the fjord system}

The validation showed that the overall performance of the wave model is good, but obviously dependent on the quality of the forcing wind fields. However, considering the specific geometry and the narrowness of the fjords, only certain wind and swell conditions generate waves inside the fjords that may influence marine traffic or constructions. The highest mean value of $H_{\mathrm{s}}, 1.3 \mathrm{~m}$, was seen at location D at the entrance of the fjord. The mean value of $H_{\mathrm{S}}$ was lowest at locations $\mathrm{C}$ and $\mathrm{F}(0.2 \mathrm{~m})$ inside the fjord. Interestingly, the mean wind speed was considerably higher for location $\mathrm{F}$ than location $\mathrm{C}$. The mean and 99.9th percentile for all locations are shown in Table 3. The case with the strongest onshore wind in location D (most exposed site) was on December 26, 2016 at 23:00 UTC and the case with the strongest offshore winds in location $\mathrm{F}$ (most sheltered site) was on January 15, 2018 at 07:00 UTC. These cases are marked with blue lines in Fig. 7. The onshore winds in the area are usually combined with incoming swell from the open ocean inducing high waves that penetrate into the fjord system. Also strong offshore winds can induce relatively high waves inside the fjords. During this type of events, the accuracy of the forcing wind field becomes even more important, since the wave fields consists mostly of local wind sea. We study these two cases in more detail to evaluate how the different wind forcing and the accuracy of the boundary wave spectra affect the wave simulations in the fjords.

\subsubsection{Onshore wind}

On December 26, 2016, the extratropical cyclone causing the extreme weather "Urd" made landfall on the west coast of Norway with strong northwesterly mean winds 
Fig. $5 Q-Q$ plots of wind speed, $H_{\mathrm{S}}$ and $T_{m 01}$ at locations D, A, $\mathrm{B}, \mathrm{C}$, and $\mathrm{F}$ for different models SWAN-ERA5 (black), SWAN-NORA10 (green), SWAN-AR2.5 (red), SWAN-WRF0.5 (blue), and SWAN-NWF (cyan)

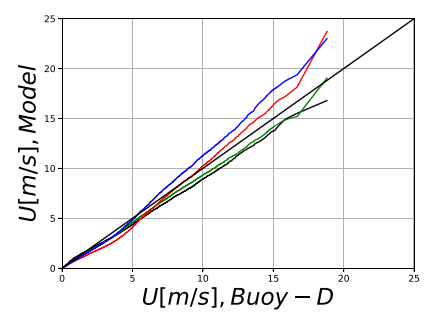

(a)

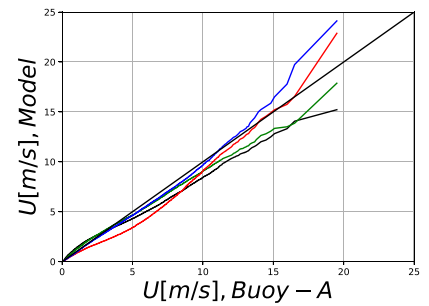

(d)

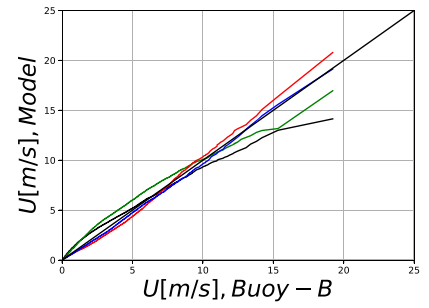

(g)

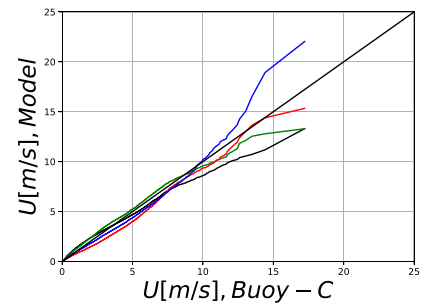

(j)

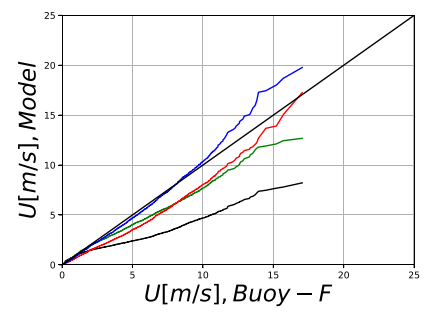

(m)

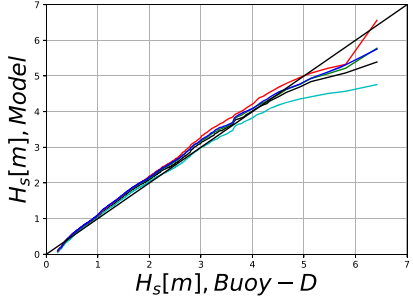

(b)

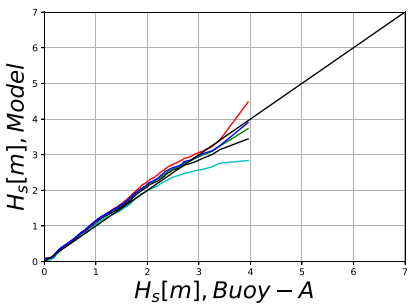

(e)

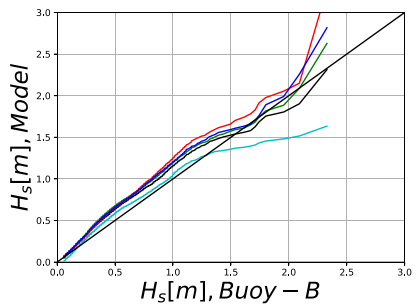

(h)

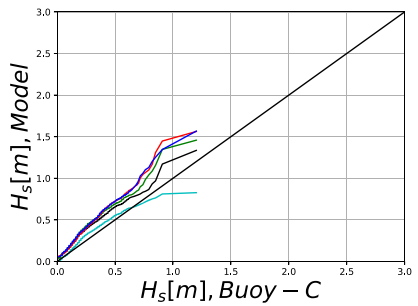

(k)

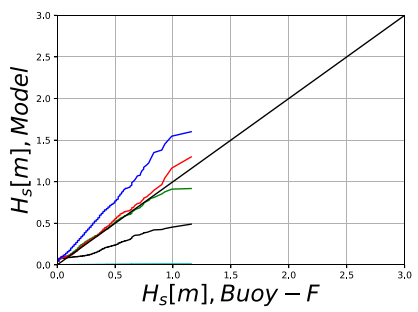

(n)

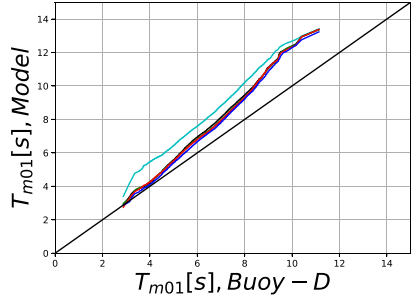

(c)

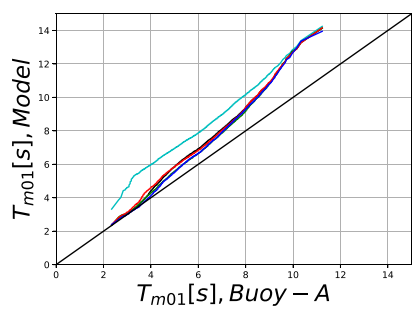

(f)

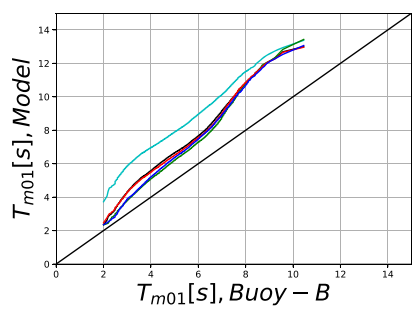

(i)

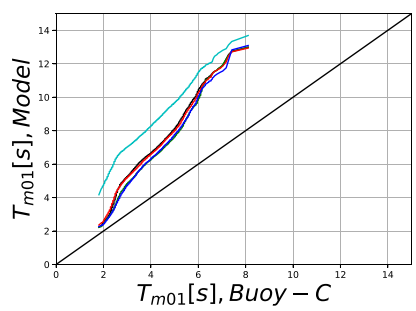

(1)

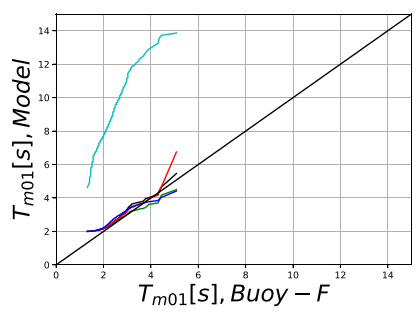

(o)
20-40 $\mathrm{m} \mathrm{s}^{-1}$ and gusts up to $53 \mathrm{~m} \mathrm{~s}^{-1}$, according to Olsen and Granerød (2017). The situation caused waves with $H_{\mathrm{s}}$ in excess of $6 \mathrm{~m}$ measured at location D.

Although onshore wind is relatively simple to model considering the absence of complex topography, differences in model wind fields are observed (Fig. 8a). The ERA5 and NORA10 winds have similar values and spatial variability along the coast while within the fjords the ERA5 shows weaker winds. In contrast to ERA5 and NORA10, the higher resolution models AR2.5 and WRF0.5 are able to capture wind channeling and local jets induced by the fjords. The AR2.5 has the strongest winds along the coast but weaker within the fjords. The WRF0.5 wind field is weaker along the coast but it has larger gradients within the fjord system. 
Fig. 6 Scatter plots between different grid size $(250 \mathrm{~m} \times 250 \mathrm{~m}$ and $1 \mathrm{~km} \times 1 \mathrm{~km})$ for $H_{\mathrm{s}}$ and $T_{m 01}$ at location $\mathrm{C}$. The values are derived by SWAN-WRF0.5 simulation

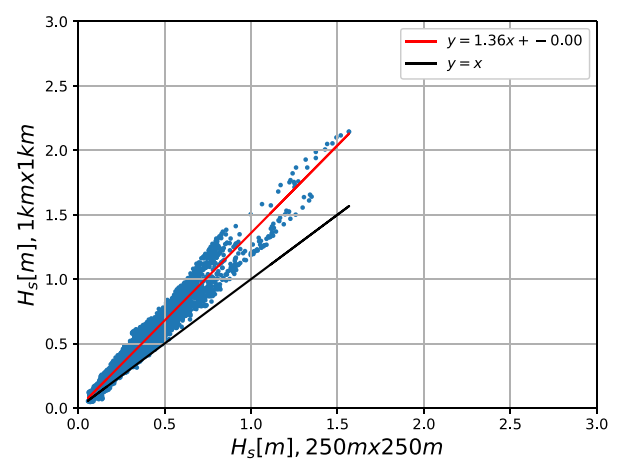

(a)

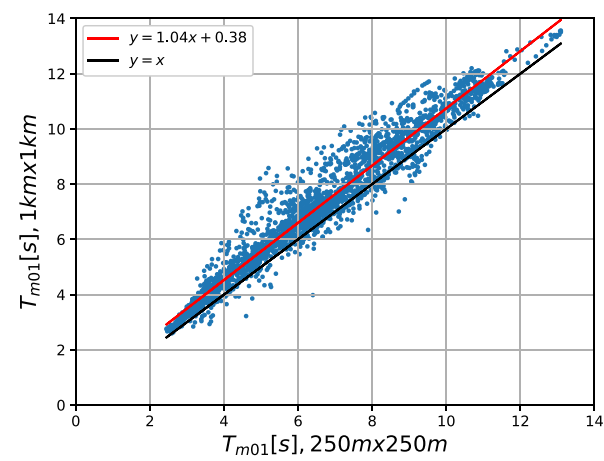

(b)
Since waves are an integrated product of the wind field in time and space, the wave fields derived from the different wind datasets reflect smoother wind characteristics as shown in Fig. 8b. In addition, the wave heights within the fjords are limited by the fjord geometry. Regarding $H_{\mathrm{s}}$ along the coast, the wave model results are quite similar with $H_{\mathrm{s}}$ exceeding $6 \mathrm{~m}$. The application of high-resolution atmosphere models, i.e, SWAN-AR2.5 and SWAN-WRF0.5, shows deeper penetration of high waves within Sulafjorden compared with SWAN-ERA5 and SWAN-NORA10. This is mainly due to stronger coastal winds and strong local winds within Sulafjorden as illustrated in Fig. 8a.

For the investigation of model performance during the event of onshore wind, we analysed the time series of wind and wave parameters at the 3 available buoy locations, D, $\mathrm{A}$, and $\mathrm{B}$, in Fig. 9. The wind speed exceeding $15 \mathrm{~m} \mathrm{~s}^{-1}$ and the westerly wind direction are captured by all models both in the inlet of Sulafjorden, location D and A, and within the fjord at location B. The high-resolution wind fields of WRF0.5 and AR2.5 overestimate the peak of wind speed. AR2.5 has the strongest wind at the peak and its overestimation is higher at location $\mathrm{D}$ and less at $\mathrm{A}$ and B. Regarding $H_{\mathrm{s}}$, the models perform similarly with good results. However, there is a 3-h delay between the highest model and observed peak of $H_{\mathrm{s}}$ at location D. Since the time of highest wind speed peak is well predicted by the models, the delay in $H_{\mathrm{s}}$ peak may be related to a delay in boundary spectrum (updated 3-hourly). At locations A and $\mathrm{B}$, the strong wind of AR2.5 and WRF0.5 drive the wave model to overestimate the $H_{\mathrm{s}}$ peak. The northwesterly wave peak direction is well predicted at locations $\mathrm{D}$ and $\mathrm{B}$ while ca. 10 degrees off at location A during the event. $T_{\mathrm{p}}$ of $12-14 \mathrm{~s}$ are simulated with high degree of accuracy by the models in all three locations.

The comparison of one-dimensional wave energy spectra between model and measured spectra for the case of onshore wind at locations $\mathrm{D}, \mathrm{A}$, and $\mathrm{B}$ (no available
Fig. 7 Time series of daily max values of $H_{\mathrm{s}}$ (top) and wind speed (bottom) at location $\mathrm{D}$ (black) and F (red). The dashed lines show the corresponding P99.9. The vertical blue lines indicate the selected extreme events that exceeds P99.9 values for both $H_{\mathrm{s}}$ and wind speed at locations D (first vertical line) and $\mathrm{F}$ (second vertical line)
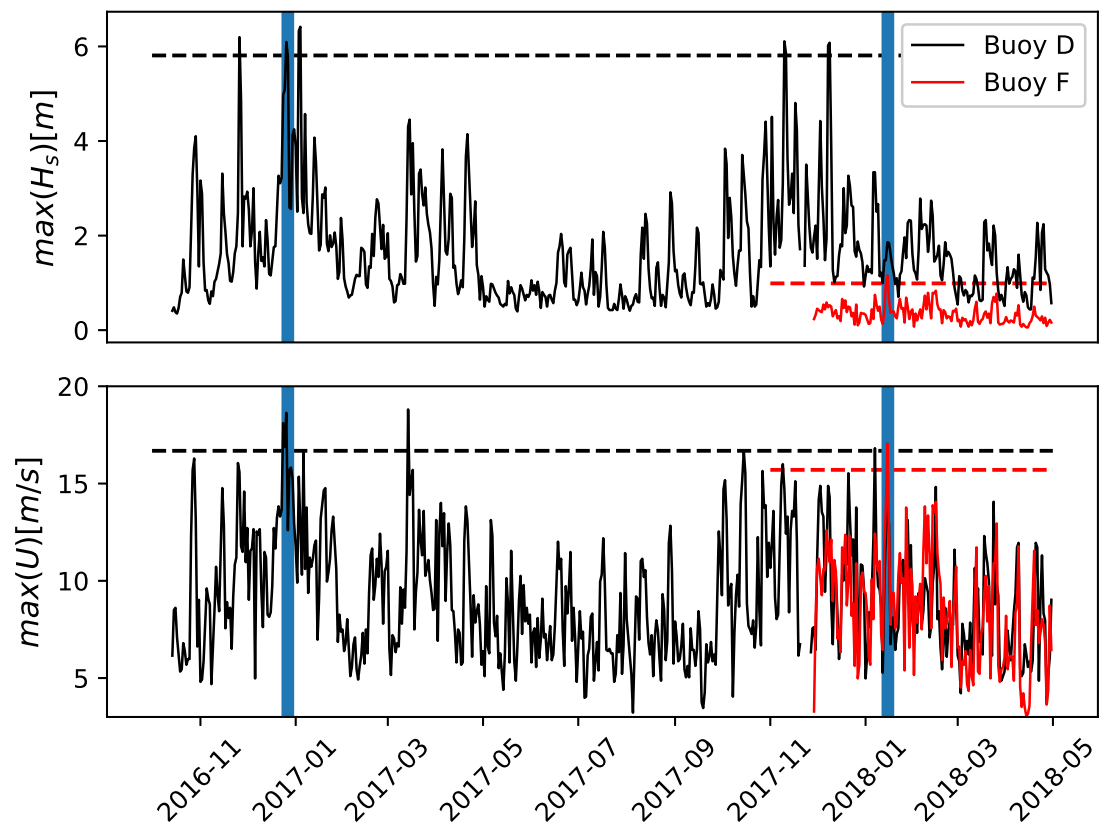

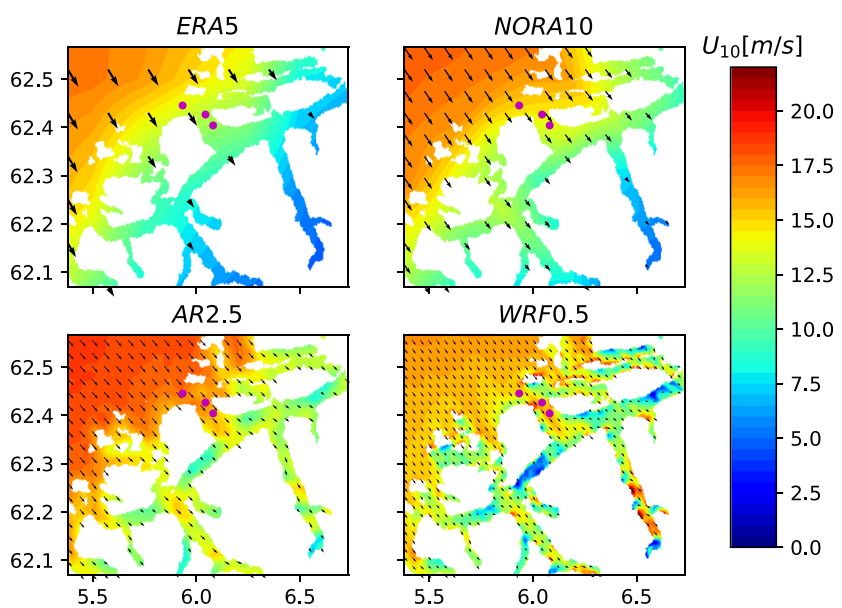

(a)

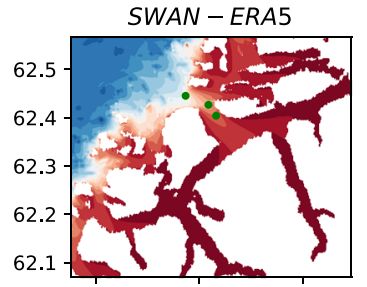

SWAN - AR2.5
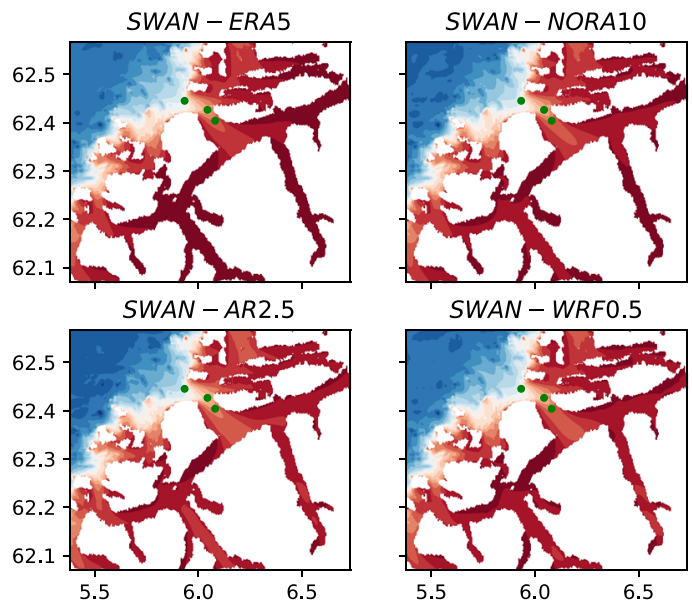

(b)

Fig. 8 Wind (a) and significant wave height (b) snapshots from different models during storm Urd on December 26, 2016 at 23:00 UTC. The location of available measurements during this event are marked with dots. The arrows indicate the wind direction

spectra data at $\mathrm{C}$ and $\mathrm{F}$ ) is presented in Fig. 10. The buoy wave spectra was averaged over the period (18 observed and 3 model spectra): December 26, 2016 at 22:00 to December 27, 2016, 00:00 UTC. The observed spectra shape at D is narrow around a single peak at $0.09 \mathrm{~Hz}$. All model setups have broader spectral shape with a peak between $0.07 \mathrm{~Hz}$ (SWAN-NWF) and $0.08 \mathrm{~Hz}$ (SWANAR2.5) which underestimates the energy level compared with the observed peak. The peak related to SWAN-AR2.5 is closest to the observed in energy level and frequency. At the inlet of Sulafjorden, location A, the density peak is reduced by $1 / 3$ in both observations and model. Similar to location $\mathrm{D}$, the density peak is underestimated by the model setups with SWAN-AR2.5 closest to observations. SWAN-AR2.5 has the strongest wind forcing and its growth of the energy at peak (location D and A) indicates that the
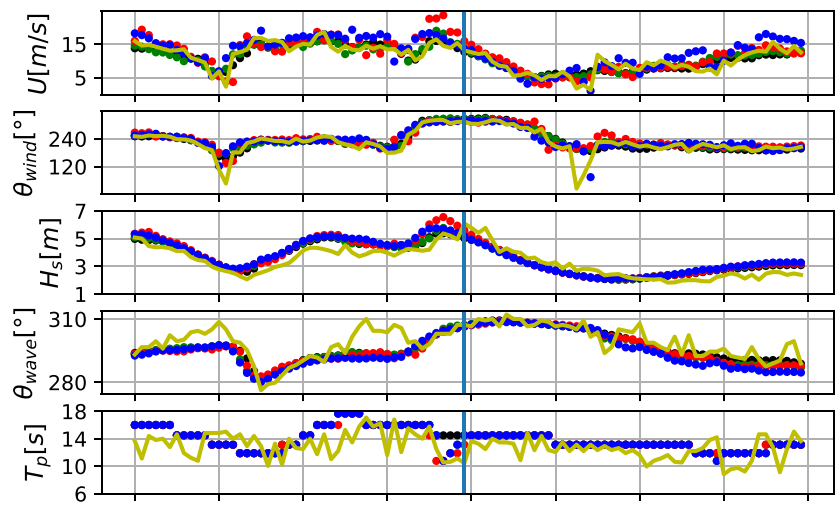

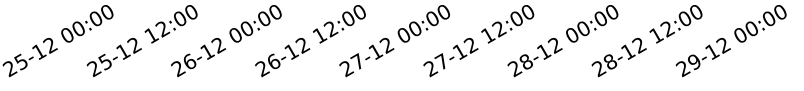

(a)
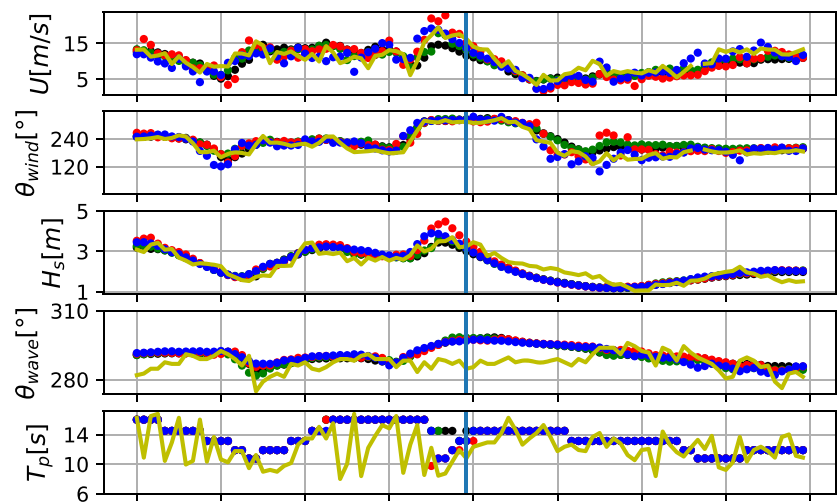

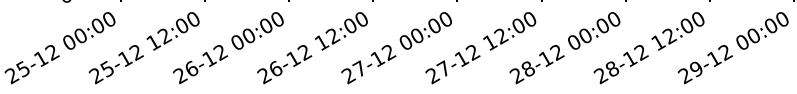

(b)
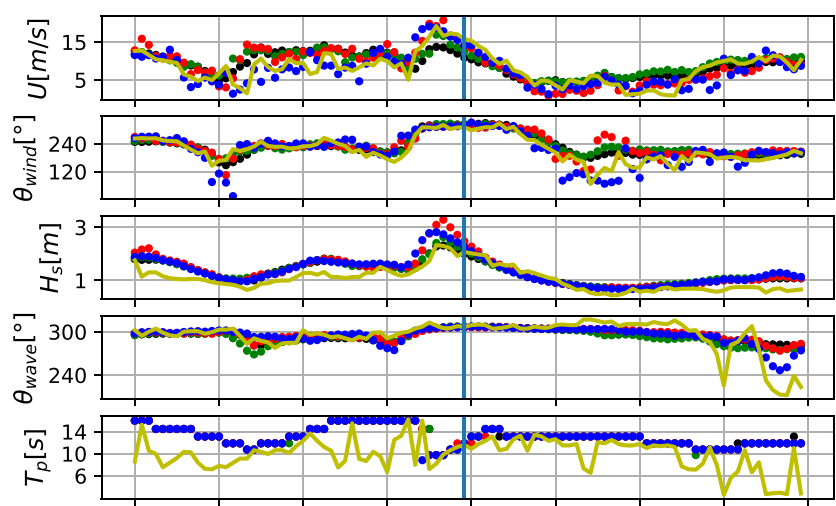

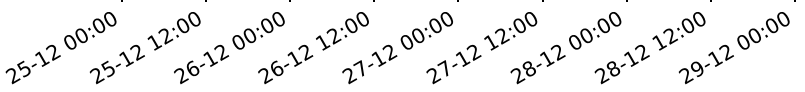

(c)

Fig. 9 Time series comparison of observed (yellow) and modeled (SWAN-ERA5: black, SWAN-NORA10: green, SWAN-AR2.5: red and SWAN-WRF0.5: blue) wind and wave parameters at location D (a) and A (b) and B (c) during the onshore wind conditions (December 26, 2016). The blue vertical line indicates the time of snapshot in Fig. 8 
long waves are still under influence of winds. However, the spectra tail is overestimated by SWAN-AR2.5. The absence of wind forcing in NWF simulations naturally results to an underestimation of both the density peak and spectra tail at locations D and A. In these locations, the density peak is quite similar to the SWAN-ERA5 and SWAN-NORA10, emphasizing the role of incoming swell at these locations. Within Sulafjorden at location B, we observe the development of a double-peaked spectra of locally generated wind sea in combination with the swell in Sulafjorden. The energy level of long waves is reduced by 3.5 times compared with location A. The spectral peak is now well represented in AR2.5 but is still underestimated by all other model setups. This is related to the higher winds in the open sea areas, which are still able to elevate the wave energy before it enters the fjord system. The peak of wind sea at around $0.25 \mathrm{~Hz}$ is overestimated in energy by the models SWAN-WRF0.5. SWAN-AR2.5, SWAN-NORA10, and SWAN-ERA5 and located at lower frequency of $0.2 \mathrm{~Hz}$. In addition, a small difference between the observed and model peak frequency can be explained either by a small fail in boundary spectra or/and the wave propagation through an area of islands and islets outside the fjord system.

\subsubsection{Offshore wind}

On January 15, 2018, there was an event of strong southeasterly wind exceeding $15 \mathrm{~m} \mathrm{~s}^{-1}$ within the fjord system, generating a strong wind sea misaligned with an incoming swell from the open sea. Figure 11 a presents a snapshot of the wind fields from the four atmospheric models during this event. In this case, the wind field is influenced by the complex orography and significant differences are visible. NORA10 and ERA5 winds both have low spatial variability but NORA10 shows a stronger wind field both offshore and in the fjords. AR2.5 and WRF0.5, due to their high resolution which is comparable with the fjord geometry, show areas of intensification and lee effects related to the topography. WRF0.5 has the highest winds both on the coast and within the fjords with stronger jets leading to strong horizontal gradients and high spatial variability.

Figure $11 \mathrm{~b}$ shows a snapshot of $H_{\mathrm{s}}$ as derived using different wind forcing at the same event. The wave field again reflects the characteristics of different wind fields in a smoother way. Although the model setups show similar results along the coast, significant differences are observed within the fjords. SWAN-ERA5 results show the lowest $H_{\mathrm{s}}<0.55 \mathrm{~m}$ within the fjords with no spatial variability reflecting the applied low wind forcing. SWANNORA10 shows a slightly higher spatial variability within the fjords with $H_{\mathrm{s}}<1.1 \mathrm{~m}$. SWAN-AR2.5 and SWANWRF0.5 wave fields reflect the presence of jets within the fjords showing higher spatial variability and local maximum at fjord cross-sections generated by the strong jets. Both SWAN-AR2.5 and SWAN-WRF0.5 result in a local maximum of $H_{\mathrm{s}}$ exceeding $1.1 \mathrm{~m}$ at the crosssection of Storfjorden (1) and Hjørundfjorden (2). For the investigation of model performance during the event of offshore winds, we analysed the time series of wind and wave parameters at the 5 buoy locations, D, A, B, and C in Fig. 12 and $\mathrm{F}$ in Fig. 13.

For the exposed locations D and A, wind speed is overestimated by WRF0.5, AR2.5, and NORA10 and it is underestimated by ERA5. The wind direction is from southeast and it is well predicted by all models. All models overestimate $H_{\mathrm{s}}$, with the highest overestimation by WRF0.5. At location D, the observed mean wave direction is from west indicating the direction of incoming swell which is well predicted by the models. However, at location $\mathrm{A}$, the observed mean wave direction turns from 270 to $220^{\circ}$. These deviations are captured better with SWAN-WRF0.5 and SWAN-AR2.5. The models show good performance to simulate the peak periods of long waves with $T_{\mathrm{p}}$ ca. $14 \mathrm{~s}$ during this event at $\mathrm{D}$ and $\mathrm{A}$.

For locations within Sulafjorden at B and C, the model results vary more than at locations $\mathrm{D}$ and $\mathrm{A}$. At location B, WRF0.5 and NORA10 show the best performance with slightly overestimation of the wind speed while at location C, AR2.5 and NORA10 perform better. In both locations,

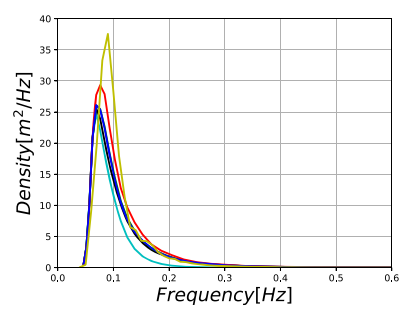

(a)

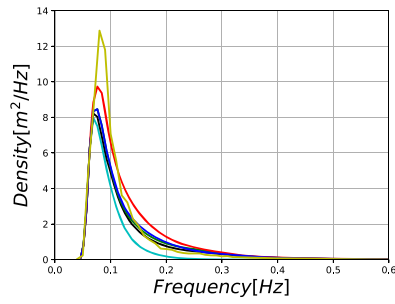

(b)

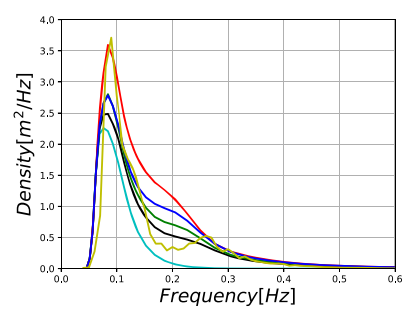

(c)
Fig. 10 Comparison of one-dimensional wave energy density, averaged during period: December 26, 2016 at 22:00 to December 27, 2016 00:00 UTC, between model(SWAN-ERA5: black, SWAN-NORA10: green, SWAN-AR2.5: red, SWAN-WRF0.5: blue and SWAN-NWF: cyan) and measured spectra (yellow) for case of onshore wind at location D (a), A (b), and B (c). The energy density ( $y$-axis) is adjusted to different location 
Fig. 11 Wind (a) and significant wave height (b) snapshots from different models during an offshore wind event on January 15, 2018, at 07:00 UTC. The location of available measurements during this event are marked with dots. The arrows indicate the wind direction
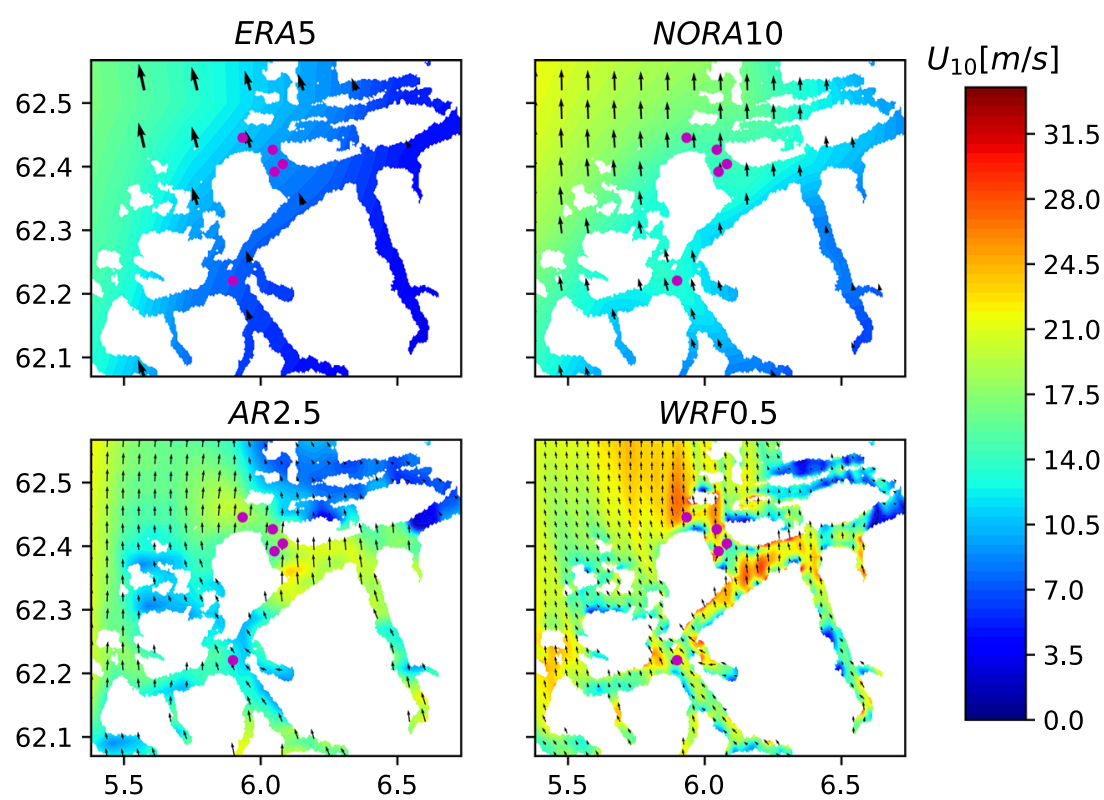

(a)

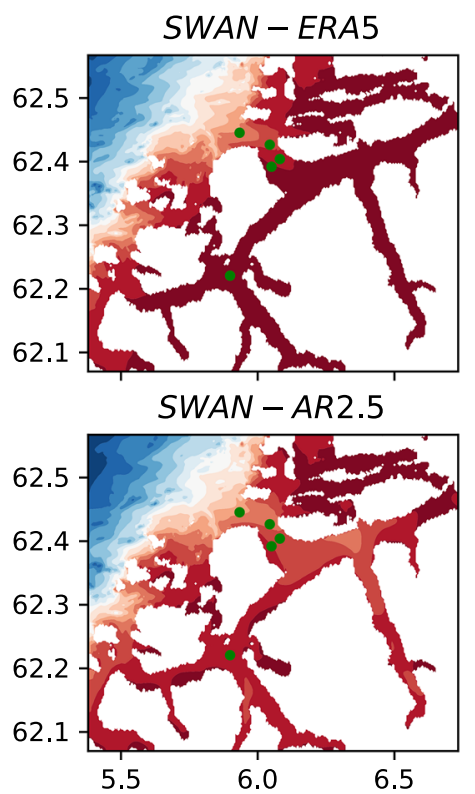

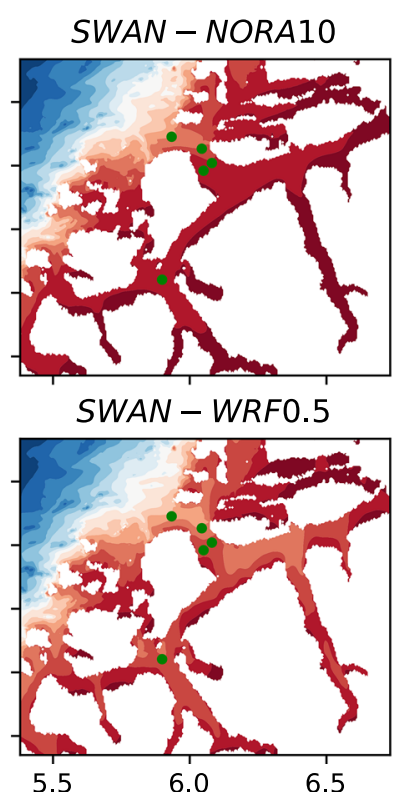

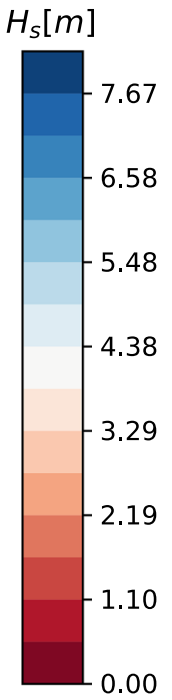

(b)
ERA5 underestimates the wind speed. The southeasterly wind direction is simulated well for all models. Following the overestimation of wind speed, SWAN-WRF0.5, SWANAR2.5, and SWAN-NORA10 predict higher values for $H_{\mathrm{s}}$ and SWAN-ERA5 gives good results in $H_{\mathrm{S}}$ in spite of the low wind speed. In contrast to SWAN-WRF0.5, SWANAR2.5 and SWAN-NORA10 predict wave direction with good accuracy. SWAN-ERA5 is not able to capture the deviation in wave direction from 260 to $180^{\circ}$ in location B. The observed $T_{\mathrm{p}}$ is lower than $6 \mathrm{~s}$ in both locations showing that the wind sea is dominant in these locations. The results indicate that only the higher resolution wind fields provide realistic $T_{\mathrm{p}}$ and wave direction within Sulafjorden.

For location $\mathrm{F}$ in Vartdalsfjorden, the observed wind speed of $16 \mathrm{~m} \mathrm{~s}^{-1}$ is the highest during this event. WRF0.5 slightly overestimates the observed wind by $2-3 \mathrm{~m} \mathrm{~s}^{-1}$. AR2.5 and NORA10 winds range 10-15 $\mathrm{m} \mathrm{s}^{-1}$. ERA5 winds are weaker $\left(<10 \mathrm{~m} \mathrm{~s}^{-1}\right)$. The strong wind speed with a southeasterly wind direction along Voldsfjorden (5) illustrates a phenomenon of wind channeling due to orography. Both wind and wave directions are predicted well by all models. However, the modeled $H_{\mathrm{s}}$ and $T_{\mathrm{p}}$ deviate 
Fig. 12 Time series comparison of observed (yellow) and modeled (SWAN-ERA5: black, SWAN-NORA10: green, SWAN-AR2.5: red and SWAN-WRF0.5: blue) wind and wave parameters at location $\mathrm{D}$ (top-left), A (top-right), B (bottom-right) and $\mathrm{C}$ (bottomleft) during the offshore wind conditions (January 15, 2018). The blue vertical line indicates the time of snapshot in Fig. 11
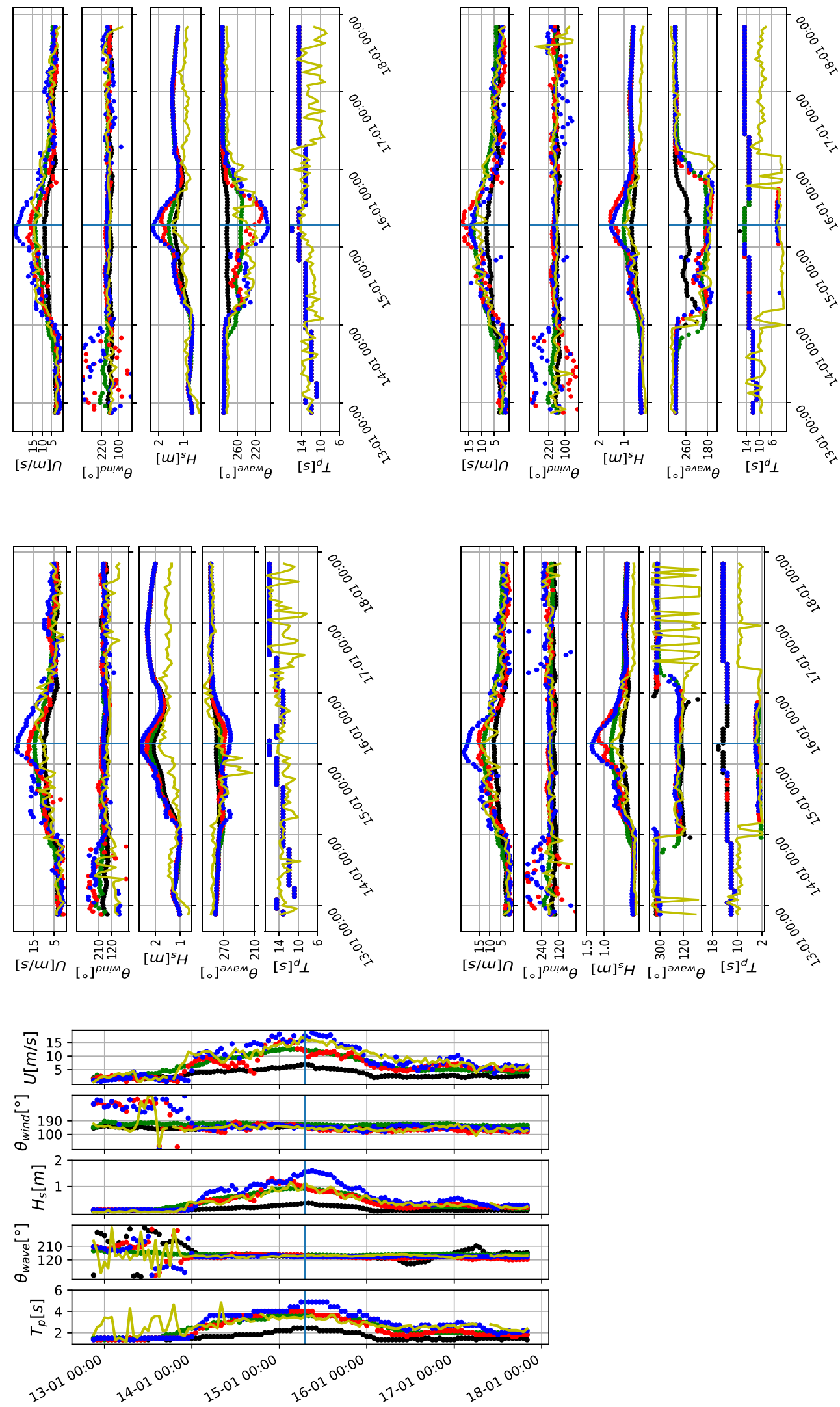

Fig. 13 Time series comparison of observed (yellow) and modeled (SWAN-ERA5: black, SWAN-NORA10: green, SWAN-AR2.5: red and SWAN-WRF0.5: blue) wind and wave parameters at location F during the offshore wind conditions (January 15, 2018).The blue vertical line indicates the time of snapshot in Fig. 11 
from the observations. The overestimation of wind forcing by WRF0.5 leads to over-estimation of $H_{\mathrm{s}}$ by $0.6 \mathrm{~m}$ and $T_{\mathrm{p}}$ by $1 \mathrm{~s}$ while ERA5 leads to underestimation. On the other hand, the wind forcing of AR2.5 and NORA10 gives the best results compared with observations of both $H_{\mathrm{S}}$ and $T_{\mathrm{p}}$. Due to weak ERA5 wind forcing, the corresponding $H_{\mathrm{s}}$ and $T_{\mathrm{p}}$ are underestimated. The results indicate a strong dependency of wave parameters on local wind conditions.

\subsection{Effect of wind forcing during extremes}

To investigate the effect of different wind forcing within the fjord system, we estimated the $H_{\mathrm{s}}$ difference between wave simulations with and without wind forcing. This allows us to detect areas where the wave estimates are affected significantly by the resolution of wind forcing. Figure 14 illustrates the difference between the 99th percentile (P99) of $H_{\mathrm{s}}$ forced by ERA5, NORA10, AR2.5, and WRF0.5 with the P99 of $H_{\mathrm{S}}$ with no wind forcing for the 19month period (October 1, 2016-April 30, 2018). The highresolution wind fields of WRF0.5 and AR2.5 show high differences up to $1.60 \mathrm{~m}$ and $1 \mathrm{~m}$ in the intersection of Storfjorden (1), Hjørundfjorden (2), and Vartdalsfjorden (4). A second area with large $H_{\mathrm{S}}$ differences is the intersection of Vartdalsfjorden (4), Voldsfjorden (5), and Rovdefjorden (6) (in location F) with differences of $1 \mathrm{~m}$ and $0.7 \mathrm{~m}$, respectively. These areas are also seen in NORA10 but less distinctly so. On the other hand, SWAN-ERA5, due to its coarse resolution of wind field, is not able to capture these differences. In addition to these high $H_{\mathrm{s}}$ difference areas within the fjord system, we observe high differences along the coast up to $1 \mathrm{~m}$ for SWAN-NORA10, SWAN-AR2.5, and SWAN-WRF0.5 and up to 0.7 for SWAN-ERA5. In contrast to areas with large differences in $H_{\mathrm{s}}$, Sulafjorden show low difference for all models indicating the dominant role of swell over wind sea in this fjord.

\section{Discussion}

The wave climate on the Norwegian coast with islands, islets and fjords is a challenge to model correctly in both the inner and outer parts. In such areas, in addition to the uncertainties due to the physics and choices in the setup in wave models, the quality of the boundary conditions, i.e. spectra on the open boundaries and wind input significantly affect the results. The quality of wind fields in complex terrain is related to the grid size of the atmosphere model. Within the fjord system, the finest grid of WRF0.5 shows the best performance in terms of variability while the coarse ERA5 winds are too weak. As the spatial resolution increases, terrain features of fjords such as high mountains and steep slopes become better resolved. Since the average fjord narrowness (width) is $2.9 \mathrm{~km}$, only atmosphere models with smaller grid size (e.g., WRF0.5 and AR2.5) are capable of reproducing the topographic features. Especially during extreme wind events within the fjords, the fine grid of WRF0.5 and AR2.5 can capture local wind phenomena such as wind channeling induced by the orography illustrating a more realistic structure (Figs. 8a and 11a). However, the
Fig. 14 The P99 of $H_{\mathrm{s}}$ difference between SWANERA5, SWAN-NORA10, SWAN-AR2.5, SWAN-WRF0.5 and SWAN-NWF
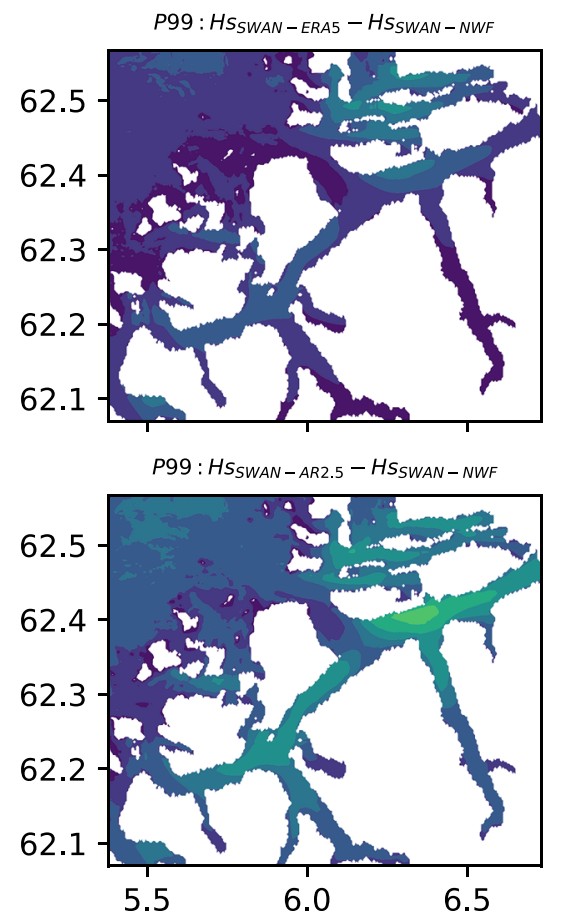

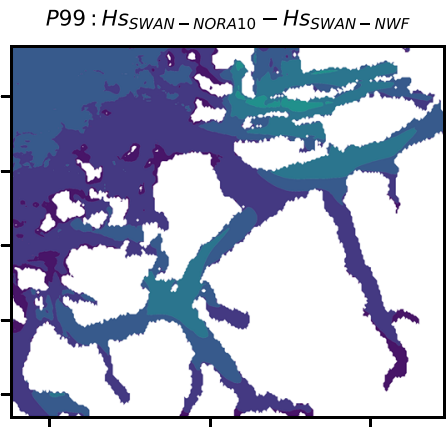

[m]

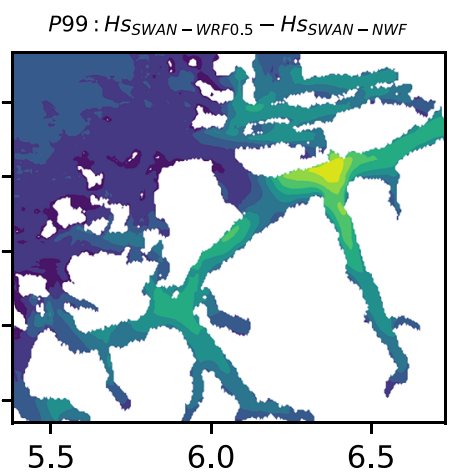

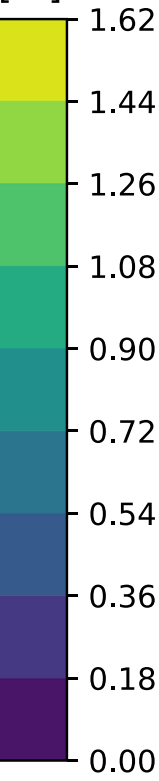

1.62

1.44

1.26

1.08

0.90

0.72

0.54

0.36

0.18

0.00 
high-resolution models have been shown to overestimate the wind speeds especially during high wind and storm events which is also observed in other studies (Signell et al. 2005).

Regarding the overall performance of the wave model SWAN, we found that it was able to simulate well the wave conditions in and close to the entrance of the fjords, where the swell is dominant (D and A). Further inside the fjord system, e.g., within Sulafjorden (B and C), the wind sea becomes more dominant and the accuracy of the wind input more significant (Fig. 4b). Even if $\mathrm{B}$ and $\mathrm{C}$ are in quite close distance (ca. $2 \mathrm{~km}$ ), $\mathrm{C}$ is more sheltered from offshore wave conditions making it more sensitive to different wind forcing. It is noteworthy that the poorest model performance is observed in the locations least exposed to the open sea where swell is weak or absent (C and F). In location F, the effect of swell is absent (in both model and observed data) and the wind forcing alone controls the wave climate. Due to its location in the intersection of three long and narrow fjords (Vartdalsfjorden (4), Voldsfjorden (5), and Rovdefjorden (6)), the fjord geometries (width: $2.5-3 \mathrm{~km}$, length: $17-25 \mathrm{~km}$ ) and the relative high mountains which surround them (height: up to $1000 \mathrm{~m}$ ) complicate the wind and consequently the wave prediction. The results show poor overall error metrics and large deviations between the different model setups. The ERA5 wind is too weak to provide good wave results. Comparing observations to $H_{\mathrm{s}}$ derived by a coarse grid $(1 \mathrm{~km} \times 1 \mathrm{~km})$ and a fine grid $(250 \mathrm{~m} \times 250 \mathrm{~m})$, we observe that the use of a nested finer grid improves the quality of results (see Fig. 6). For instance, $H_{\mathrm{s}}$ of the fine grid is more accurate at location $\mathrm{D}$ by $4 \%, \mathrm{~A}$ by $15 \%, \mathrm{C}$ by $36 \%$ and B by $1 \%$ (shown only for C). In contrast, at location $\mathrm{F}$, the coarse grid gives slightly better results (not shown). Thus, a higher spatial resolution $(<250 \mathrm{~m})$ may improve the results at location $\mathrm{C}$ but not in $\mathrm{F}$ where the problem seems to be related to different factors (discussed below). No improvement in wave estimates $\left(H_{\mathrm{s}}\right.$ and $\left.T_{m 01}\right)$ are found by increasing the directional resolution from 10 to 5 degrees (not shown).

Even if overall wave statistics are good, during extreme conditions the quality of wind forcing becomes a crucial factor since the coarse wind fields are much weaker at all locations. At the outer locations, D and A, strong coastal wind affects significantly the wave conditions. Our results indicate that the highest $H_{\mathrm{S}}$ cannot be reached without wind forcing. More specific, during the onshore wind case, AR2.5 has the highest spectral peak indicating that its higher coastal wind enhances (Fig. 8a) the energy level of incoming long waves which lead to a deeper penetration of offshore waves within Sulafjorden (Fig. 8b) but impairs the spectral shape. However, the higher resolution forcing did not lead to a better wave model performance in all situations. In location $\mathrm{F}, H_{\mathrm{S}}$ is overestimated by up to $0.5 \mathrm{~m}$ with WRF0.5 wind forcing even if WRF0.5 provides the best wind at the location with only a slight overestimation (2$3 \mathrm{~m} \mathrm{~s}^{-1}$ ) of the high wind speed. Here, NORA10 and AR2.5 show weaker wind, but still providing more accurate wave heights. Due to relative short availability of measurement data (ca. 6 month) at location F, it is difficult to make firm conclusions. We expect that the overestimation by SWANWRF0.5 is related to the calibration of deep water source terms and the accuracy of wind forcing along the fjord. Due to large depth of this region, only the source terms of wind input, whitecapping dissipation and non-linear wave-wave interactions (quadruplet) are of significant importance. In case of strongly forced waves (inverse wave age greater than 0.1), van der Westhuysen et al. (2007) indicated that the wind input formulation becomes non-linear i.e. the rate of wind-induced growth has a quadratic dependency on the inverse wave age. During these conditions, small differences in wind forcing can have significant impact on wave conditions. Therefore, a re-calibration of wind input or/and whitecapping dissipation may improve the model estimates at location F. Mao et al. (2016) showed that a re-calibration of whitecapping formulation leads to improvements in model performance. Nevertheless, this may have negative effect on the other locations. Another important factor is the accuracy of wind forcing, even if WRF0.5 shows an overall good performance, our evaluation is based on point measurement not allowing accurate conclusion about the wind quality along the fjord. Considering that the offshore winds are more challenging to predict due to the complexity of topography in the region, the accuracy of wind along the fjords plays an significant role on the wave growth. Similar coastal wave studies by Tuomi et al. (2014b) have shown that the higher resolution wind forcing does not necessarily lead to better wave model performance.

Compared with $H_{\mathrm{s}}$, wave period is a more challenging parameter to model. Simulations of $T_{m 01}$ with wind forcing perform similarly while the simulations of NWF clearly fails at all locations. Nevertheless, if the boundary spectra are estimated with too low/high energy level by the offshore wave hindcast (NORA10), the coastal wave model may not be able to correct this inaccuracy. For high mean wave periods, Reistad et al. (2011) found that NORA10 overestimates the observed data indicating that certain swell conditions may not be well predicted. These potential inaccuracies in our boundary spectra are consequently transferred in the coastal wave predictions. This becomes clear in locations D and A where SWAN overestimates the observed wave periods for $T_{m 01}>4 \mathrm{~s}$ (Fig. 5). The inaccurate model results at location $\mathrm{C}$ are also observed in mean wave period. The modelled $T_{m 01}$ for $\mathrm{C}$ is similar to $\mathrm{B}$, over-predicting the observed values; however, the highest observed periods are reduced by $2 \mathrm{~s}$, i.e., from 10 to $8 \mathrm{~s}$, indicating that the model is not able to capture accurately the reduction of $T_{m 01}$ for long waves within Sulafjorden. 
The model fails to capture the sheltering effects at location $\mathrm{C}$ due to the sheltering of the island to the southwest. Based on our simulations, the $T_{m 01}$ was improved by the use of a nested fine grid of $250 \mathrm{~m}$. Therefore, an increase of spatial resolution $(<250 \mathrm{~m})$ rather than directional resolution may resolve better these sheltering effects improving $T_{m 01}$ estimates.

Most of available buoy measurements (4 out of 5) are located in the inlet and within Sulafjorden allowing us to validate the modelled wind and wave estimates in a fjord with exposure to open sea conditions. However, there is a need for more measurements within the fjord system where large differences between the models are observed. For instance, the highest $H_{\mathrm{s}}$ differences (Fig. 14) are observed in the intersection of Storfjorden (1), Hjørundfjorden (2) and Vartdalsfjorden (4) where there are no available observations and therefore it is not possible to extract any information about the model performance.

Finally, the choice of wind input should be decided by the area of interest. Along the coastline and in exposed locations to open sea, the coarse wind fields can give reasonable wave estimates since the quality of boundary wave spectra is most important. Inside the fjord system, the fjord geometry is the key factor for the selection of the spatial resolution of wind forcing. However, in narrow fjords where a high resolution wind field is needed, possible overestimation of high winds can lead to significant overestimation of waves such as in location F. Therefore, methods such as tuning of source terms should be considered for future model implementations.

\section{Conclusions}

In this study, SWAN is set up for a fjord system on the west coast of Norway. Simulations with four different wind forcing (with spatial resolution; $0.5 \mathrm{~km}, 2.5 \mathrm{~km}, 10 \mathrm{~km}$, and $31 \mathrm{~km}$ ) and one with no wind were applied to assess the wave model quality. Both modeled wind and wave are compared with observations from five measurement sites. The performance of the wave model is better for the exposed locations where swell conditions are dominant. The poorest model performance is observed in the locations least exposed to the open sea where swell is weak or absent (locations $\mathrm{C}$ and $\mathrm{F}$ ). The fine grid of WRF0.5 captures local wind phenomena such as wind channeling, but leads to overestimation of the waves within the fjords (location F). This is believed to be due to a tuning of SWAN to coastal conditions. Our results show that the wave estimates at location $\mathrm{C}$ may be improved by increasing the spatial resolution $(<250 \mathrm{~m})$. During extreme situations, the local wind-induced waves become crucial for the accuracy of wave estimates and especially for the most exposed locations, where the high resolution wind forcing fields (WRF0.5 and AR2.5) give better results. Pure wave propagation without local wind forcing fails to reproduce realistic mean wave periods and the highest significant wave height in any of the locations.

Acknowledgments We would like to thank the anonymous reviewers for their suggestions and comments that improved the manuscript. We are grateful to Lasse Lønseth (Fugro OCEANOR AS) who provided the wave spectral data. Wind and wave measurements were available via MET Norway Thredds Service at Norwegian Meteorological Institute. Finally, we would like to thank EMODnet Bathymetry Consortium (2018) for the bathymetry data and the SWAN team at Delft University of Technology, The Netherlands for developing the SWAN wave model.

Funding information This study was supported by the Norwegian Public Roads Administration under the Coastal Highway Route E39 project.

Open Access This article is distributed under the terms of the Creative Commons Attribution 4.0 International License (http:// creativecommons.org/licenses/by/4.0/), which permits unrestricted use, distribution, and reproduction in any medium, provided you give appropriate credit to the original author(s) and the source, provide a link to the Creative Commons license, and indicate if changes were made.

\section{References}

Aarnes OJ, Breivik Ø, Reistad M (2012) Wave extremes in the Northeast, Atlantic. J Clim 25(5):1529-1543. https://doi.org/10.1175/ JCLI-D-11-00132.1

Akpnar A, van Vledder GP, hsan Kömürcü M, Özger M (2012) Evaluation of the numerical wave model (swan) for wave simulation in the black sea. Cont Shelf Res 50-51:80 - 99. https://doi.org/10. 1016/j.csr.2012.09.012, http://www.sciencedirect.com/science/arti cle/pii/S0278434312002671

Alves JHGM, Banner ML (2003) Performance of a saturationbased dissipation-rate source term in modeling the fetch-limited evolution of wind waves. J Phys Oceanogr 33(6):1274-1298

Amarouche K, Akpinar A, Bachari NEI, Çakmak R, Houma F (2019) Evaluation of a high-resolution wave hindcast model SWAN for the west Mediterranean basin. Appl Ocean Res 84:225-241. https://doi.org/10.1016/j.apor.2019.01.014

Ardhuin F, Bertotti L, Bidlot J, Cavaleri L, Filipetto V, Lefevre JM, Wittmann P (2007) Comparison of wind and wave measurements and models in the western Mediterranean sea. Ocean Eng 34:526541. https://doi.org/10.1016/j.oceaneng.2006.02.008

Babanin A (2011) Breaking and dissipation of ocean surface waves. Breaking and Dissipation of Ocean Surface Waves. doi:10.1017/CBO9780511736162

Battjes J, Janssen J (1978) Energy loss and set-up due to breaking random waves. Proceedings of 16th Conference on Coastal Engineering, ASCE, pp 569-588

Belmonte Rivas M, Stoffelen A (2019) Characterizing ERA-interim and ERA5 surface wind biases using ASCAT. Ocean Sci 15(3):831-852. https://doi.org/10.5194/os-15-831-2019, https:// www.ocean-sci.net/15/831/2019/

Bertotti L, Cavaleri L, Soret A, Tolosana-Delgado R (2014) Performance of global and regional nested meteorological models. Cont Shelf Res 87:17 - 27. https://doi.org/10.1016/j.csr.2013.12.013, 
http://www.sciencedirect.com/science/article/pii/S027843431400 0053, oceanography at coastal scales

Bidlot JR, Holmes DJ, Wittmann PA, Lalbeharry R, Chen HS (2002) Intercomparison of the performance of operational ocean wave forecasting systems with buoy data. Weather Forecast 17(2):287310. https://doi.org/10.1175/1520-0434(2002)017<0287:IOTPO $\mathrm{O}>2.0 . \mathrm{CO} ; 2$

Bjørge D, Haugen JE, Homleid M, Vignes O, Ødegaard V (2003) Updating the HIRLAM numerical weather prediction system at met.no 2000-2002. Tech. Rep. 145, Norwegian Meteorological Institute

Booij N, Ris RC, Holthuijsen LH (1999) A third-generation wave model for coastal regions: 1. model description and validation. $\mathrm{J}$ Geophys Res: Oceans 104(C4):7649-7666. https://doi.org/10.10 29/98JC02622

Breivik Ø, Gusdal Y, Furevik BR, Aarnes OJ, Reistad M (2009) Nearshore wave forecasting and hindcasting by dynamical and statistical downscaling. J Mar Syst 78(2):S235-S243. https://doi. org/10/cbgwqd

Bruserud K, Haver S (2016) Comparison of wave and current measurements to NORA10 and NoNoCur hindcast data in the northern North Sea. Ocean Dyn 66(6):823-838. https://doi.org/10.1007/ s10236-016-0953-z

Cavaleri L, Sclavo M (2006) The calibration of wind and wave model data in the Mediterranean Sea. Coast Eng 53(7):613-627. https://doi.org/10.1016/j.coastaleng.2005.12.006, http://www. sciencedirect.com/science/article/pii/S0378383906000020

Cavaleri L, Abdalla S, Benetazzo A, Bertotti L, Bidlot JR, Breivik $\emptyset$, Carniel S, Jensen R, Portilla-Yandun J, Rogers W, Roland A, Sanchez-Arcilla A, Smith J, Staneva J, Toledo Y, van Vledder G, van der Westhuysen A (2018) Wave modelling in coastal and inner seas. Progress in Oceanography. https://doi.org/10.1016/j.pocean. 2018.03.010

Christakos K, Varlas G, Reuder J, Katsafados P, Papadopoulos A (2014) Analysis of a low-level coastal jet off the western coast of Norway. Energy Procedia 53:162-172. https://doi.org/10.1016/j. egypro.2014.07.225

Copernicus Climate Change Service (C3S) (2017) ERA5: Fifth generation of ECMWF atmospheric reanalyses of the global climate. Copernicus Climate Change Service Climate Data Store (CDS), date of access: 20-01-2018. https://cds.climate.copernicus. eu/cdsapp

Dee DP, Uppala SM, Simmons AJ, Berrisford P, Poli P, Kobayashi S, Andrae U, Balmaseda MA, Balsamo G, Bauer P, Bechtold P, Beljaars ACM, van de Berg L, Bidlot J, Bormann N, Delsol C, Dragani R, Fuentes M, Geer AJ, Haimberger L, Healy SB, Hersbach H, Hólm EV, Isaksen L, Kållberg P, Köhler M, Matricardi M, McNally AP, Monge-Sanz BM, Morcrette JJ, Park BK, Peubey C, de Rosnay P, Tavolato C, Thépaut JN, Vitart F (2011) The ERA-interim reanalysis: configuration and performance of the data assimilation system. Q J R Meteorol Soc 137(656):553-597. https://doi.org/10.1002/qj.828

Taylor EK (2001) Summarizing multiple aspects of model performance in a single diagram. J Geophys Res 106:7183-7192. https://doi.org/10.1029/2000JD900719

ECMWF (2018) Part VII : ECMWF Wave Model, ECMWF, chap 10, p 70. No. 7 in IFS Documentation, https://www.ecmwf.int/node/ 18717

EMODnet (2016) Emodnet digital bathymetry (dtm). Marine Information Service. https://doi.org/10.12770/c7b53704-999d-4721-b1a304 ec60c87238

FUGRO (2012) Seawatch wavescan buoy. Brochure, https:// www.fugro.com/docs/default-source/about-fugro-doc/ROVs/ seawatch-wavescan-buoy-flyer.eps
Furevik BR, Haakenstad H (2012) Near-surface marine wind profiles from rawinsonde and NORA10 hindcast. Journal of Geophysical Research: Atmospheres 117(D23). https://doi.org/10.1029/2012 JD018523

Galanis G, Kallos G, Chu P, Kuo YH (2019) Evaluation of the new ECMWF WAM model. European Space Agency, Proc of "SeaSar 2010”, Frascati, Italy, 25-29 January 2010

Gelaro R, McCarty W, Suárez MJ, Todling R, Molod A, Takacs L, Randles CA, Darmenov A, Bosilovich MG, Reichle R, Wargan K, Coy L, Cullather R, Draper C, Akella S, Buchard V, Conaty A, da Silva AM, Gu W, Kim GK, Koster R, Lucchesi R, Merkova D, Nielsen JE, Partyka G, Pawson S, Putman W, Rienecker M, Schubert SD, Sienkiewicz M, Zhao B (2017) The modern-era retrospective analysis for research and applications, version 2 (MERRA-2). J Clim 30(14):5419-5454. https://doi.org/10.1175/JCLI-D-16-0758.1

Guedes Soares C, Salvacao N, Gonçalves M, Rusu L (2016) Validation of an operational wave forecasting system for the North Atlantic area. Taylor \& Francis Group, London, pp 10371043

Gunther SH, Janssen PAEM (1992) The WAM model cycle 4. Technical report. Deutsches KlimaRechenZentrum, Hamburg, Germany

Hasselmann K, P Barnett T, Bouws E, Carlson H, E Cartwright D, Enke K, A Ewing J, Gienapp H, E Hasselmann D, Kruseman P, Meerburg A, Muller P, Olbers D, Richter K, Sell W, Walden H (1973) Measurements of wind-wave growth and swell decay during the Joint North Sea Wave Project (JONSWAP). Deut Hydrogr Z 8:1-95

Hersbach H, Dee D (2016) ERA5 reanalysis is in production. ECMWF Newslett 147:7

Janssen PA (2008) Progress in ocean wave forecasting. J Comput Phys 227(7):3572-3594. https://doi.org/10.1016/j.jcp.2007.04.029, http://www.sciencedirect.com/science/article/pii/

S0021999107001659, predicting weather, climate and extreme events

Janssen PA, Bidlot JR (2018) Progress in operational wave forecasting. Procedia IUTAM 26:14-29. https://doi.org/10.1016/j.piutam. 2018.03.003, http://www.sciencedirect.com/science/article/pii/ S2210983818300038, iUTAM Symposium on Wind Waves

Komen G, Hasselmann K (1984) On the existence of a fully developed wind-sea spectrum. J Phys Oceanogr - J Phys Oceanogr 14:12711285. https://doi.org/10.1175/1520-0485(1984)014<1271:OTEO $\mathrm{AF}>2.0 . \mathrm{CO} ; 2$

Laloyaux P, de Boisseson E, Balmaseda M, Bidlot JR, Broennimann S, Buizza R, Dalhgren P, Dee D, Haimberger L, Hersbach H, Kosaka Y, Martin M, Poli P, Rayner N, Rustemeier E, Schepers D (2018) CERA-20C: A Coupled Reanalysis of the Twentieth Century. J Adv Model Earth Syst 10(5):1172-1195. https://doi.org/10.1029/2018MS001273

Lavidas G, Venugopal V, Friedrich D (2017) Sensitivity of a numerical wave model on wind re-analysis datasets. Dyn Atmos Oceans 77:1-16. https://doi.org/10.1016/j.dynatmoce.2016.10.007, http:// www.sciencedirect.com/science/article/pii/S0377026516301154

Mao M, van der Westhuysen AJ, Xia M, Schwab DJ, Chawla A (2016) Modeling wind waves from deep to shallow waters in lake michigan using unstructured swan. J Geophys Res: Oceans 121(6):3836-3865. https://doi.org/10.1002/2015JC011340

Martínez-Asensio A, Marcos M, Jordà G, Gomis Bosch D (2013) Calibration of a new wind-wave hindcast in the western Mediterranean. Journal of Marine Systems. https://doi.org/10.1016/j.jmar sys.2013.04.006

Moeini M, Etemad-Shahidi A, Chegini V (2010) Wave modeling and extreme value analysis off the northern coast of the persian gulf. 
Appl Ocean Res 32(2):209-218. https://doi.org/10.1016/j.apor. 2009.10.005

Müller M, Homleid M, Ivarsson KI, Køltzow MAØ, Lindskog M, Midtb $\varnothing \mathrm{KH}$, Andrae U, Aspelien T, Berggren L, Bjørge D, Dahlgren P, Kristiansen J, Randriamampianina R, Ridal M, Vignes O (2017) AROME-MetCoOp: a nordic convectivescale operational weather prediction model. Weather Forecast 32(2):609-627. https://doi.org/10.1175/WAF-D-16-0099.1

Olauson J (2018) ERA5: The new champion of wind power modelling? Renewable Energy 126. https://doi.org/10.1016/j.renene. 2018.03.056

Olsen AM, Granerød M (2017) Ekstremværapport, hendelse: Urd 26 desember 2016. Technical report, Norwegian Meteorological Institute

Poli P, Hersbach H, Dee D, Berrisford P, Simmons A, Vitart F, Laloyaux P, Tan D, Peubey C, Thepaut JN, Trémolet Y, Hólm E, Bonavita M, Isaksen L, Fisher M (2016) ERA-20C: An Atmospheric Reanalysis of the Twentieth Century. J Clim 29(11):4083-4097. https://doi.org/10.1175/JCLI-D-15-0556.1

Ponce de León S, Orfila A, Gómez-Pujol L, Renault L, Vizoso G, Tintoré J (2012) Assessment of wind models around the balearic islands for operational wave forecast. Appl Ocean Res 34:1 - 9. https://doi.org/10.1016/j.apor.2011.09.001, http://www. sciencedirect.com/science/article/pii/S0141118711000770

Reistad M, Breivik Ø, Haakenstad H, Aarnes OJ, Furevik BR, Bidlot JR (2011) A high-resolution hindcast of wind and waves for the North Sea, the Norwegian Sea, and the Barents Sea. Journal of Geophysical Research: Oceans 116(C5). https://doi.org/10.1029/ 2010JC006402

Saha S, Moorthi S, Pan HL, Wu X, Wang J, Nadiga S, Tripp P, Kistler R, Woollen 846 J, Behringer D, Liu H, Stokes D, Grumbine R, Gayno G, Wang J, Hou YT, 847 Chuang HY, Juang HMH, Sela J, Iredell M, Treadon R, Kleist D, Delst PV, 848 Keyser D, Derber J, Ek M, Meng J, Wei H, Yang R, Lord S, Van den Dool H, KumarvA, Wang W, Long C, Chelliah M, Xue Y, Huang B, Schemm JK, Ebisuzaki W, Lin R, Xie P, Chen M, Zhou S, Higgins W, Zou CZ, Liu Q, Chen Y, Han Y, Cucurull L, Reynolds RW, Rutledge G, Goldberg M (2010) NCEP Cli852 mate Forecast System Reanalysis (CFSR) selected hourly time-series products 853 January 1979 to. https://doi.org/10.5065/D6513W89

Semedo A, Vettor R, Breivik Ø, Sterl A, Reistad M, Soares CG, Lima DCA (2015) The wind sea and swell waves climate in the Nordic Seas. Ocean Dyn 65(2):223-240. https://doi.org/10.1007/s10236014-0788-4

Signell RP, Carniel S, Cavaleri L, Chiggiato J, Doyle JD, Pullen J, Sclavo M (2005) Assessment of wind quality for oceanographic modelling in semi-enclosed basins. J Mar Syst 53(1):217-233. https://doi.org/10.1016/j.jmarsys.2004.03.006

Skamarock WC, Klemp JB, Dudhia J, Gill DO, Barker M, Duda KG, Huang XY, Wang W, Powers JG (2008) A description of the Advanced Research WRF Version 3. Technical report, National Center for Atmospheric Research

Stopa JE, Cheung KF (2014) Intercomparison of wind and wave data from the ECMWF Reanalysis Interim and the NCEP climate forecast system reanalysis. Ocean Modellx 75:65 - 83. https://doi.org/10.1016/j.ocemod.2013.12.006, http://www. sciencedirect.com/science/article/pii/S1463500313002205
SWAN team (2019) Modifications. http://swanmodel.sourceforge.net/ modifications/modifications.htm

The Norwegian Coastal Administration (2019a) Map service: Kystinfo. https://kart.kystverket.no/

The Norwegian Meteorological Institute (2019b) Observational data at SVV-E39 project. http://thredds.met.no/thredds/catalog/obs/ buoy-svv-e39/catalog.html

The Wamdi Group (1988) The WAM model - a third generation ocean wave prediction model. J Phys Oceanogr 18(12):1775-1810. https://doi.org/10.1175/1520-0485(1988)018<1775:TWMTGO> 2.0.CO;2

The WAVEWATCHIII ${ }^{\circledR}$ Development Group (2016) User manual and system documentation of WAVEWATCH III ${ }^{\circledR}$ version 5.16. Tech. Note 329, NOAA/NWS/NCEP/MMAB, 326 pp. + Appendices

Troen I, Lundtang Petersen E (1989) European Wind Atlas. Ris $\varnothing$ National Laboratory

Tuomi L (2014a) On modelling surface waves and vertical mixing in the baltic sea. PhD thesis, University of Helsinki, Faculty of Science, Department of Physics, Finnish Meteorological Institute, http://hdl.handle.net/10138/42773

Tuomi L, Pettersson H, Fortelius C, Tikka K, Björkqvist JV, Kahma KK (2014b) Wave modelling in archipelagos, vol 83. https://doi.org/10.1016/j.coastaleng.2013.10.011, http://www. sciencedirect.com/science/article/pii/S0378383913001671

Undén P, Rontu L, Järvinen H, Lynch P, Calvo-Sanchez J, Cats G, Cuxart J, Eerola K, Fortelius C, García-Moya J (2002) HIRLAM-5 Scientific documentation. Technical report, Sveriges meteorologiska och hydrologiska institut

Uppala S, Kallberg P, Simmons A, Andrae U, Da Costa Bechtold V, Fiorino M, K Gibson J, Haseler J, Hernandez-Carrascal A, Kelly G, Li X, Onogi K, Saarinen S, Sokka N, Allan R, Andersson E, Arpe K, Balmaseda M, Beljaars A, Woollen J (2005) The Era-40 re-analysis. Q J R Meteorol Soc 131:2961-3012. https://doi.org/10.1256/qj.04.176

Varlas G, Christakos K, Cheliotis I, Papadopoulos A, Steeneveld GJ (2017) Spatiotemporal variability of marine renewable energy resources in Norway. Energy Procedia 125:180-189. https://doi.org/10.1016/j.egypro.2017.08.171

Vignudelli S, Kostianoy A, Cipollini P, Benveniste J (2011) Coastal Altimetry. Springer, vol 1. https://doi.org/10.1007/978-3-642-127 96-0

Wang J, Li L, Jakobsen JB, Haver SK (2018) Metocean conditions in a Norwegian fjord. Journal of Offshore Mechanics and Arctic Engineering. https://doi.org/10.1115/1.4041534

van der Westhuysen AJ, Zijlema M, Battjes JA (2007) Nonlinear saturation-based whitecapping dissipation in SWAN for deep and shallow water. Coast Eng 54(2):151-170. https://doi.org/10. 1016/j.coastaleng.2006.08.006, http://www.sciencedirect.com/sci ence/article/pii/S037838390600127X

Wieringa J (1992) Updating the davenport roughness classification. J Wind Eng Ind Aerodyn 41(1):357 - 368. https://doi.org/10.1016/ 0167-6105(92)90434-C, http://www.sciencedirect.com/science/ article/pii/016761059290434C

Yan L (1987) An improved wind input source term for third generation ocean wave modelling. Rep No 87-8, Royal Dutch Meteor Inst 